\title{
Evolution of Human Brain Atlases in Terms of Content, Applications, Functionality, and Availability
}

\author{
Wieslaw L. Nowinski ${ }^{1}$ \\ Published online: 29 July 2020 \\ (C) The Author(s) 2020
}

\begin{abstract}
Human brain atlases have been evolving tremendously, propelled recently by brain big projects, and driven by sophisticated imaging techniques, advanced brain mapping methods, vast data, analytical strategies, and powerful computing. We overview here this evolution in four categories: content, applications, functionality, and availability, in contrast to other works limited mostly to content. Four atlas generations are distinguished: early cortical maps, print stereotactic atlases, early digital atlases, and advanced brain atlas platforms, and 5 avenues in electronic atlases spanning the last two generations. Content-wise, new electronic atlases are categorized into eight groups considering their scope, parcellation, modality, plurality, scale, ethnicity, abnormality, and a mixture of them. Atlas content developments in these groups are heading in 23 various directions. Application-wise, we overview atlases in neuroeducation, research, and clinics, including stereotactic and functional neurosurgery, neuroradiology, neurology, and stroke. Functionality-wise, tools and functionalities are addressed for atlas creation, navigation, individualization, enabling operations, and application-specific. Availability is discussed in media and platforms, ranging from mobile solutions to leading-edge supercomputers, with three accessibility levels. The major application-wise shift has been from research to clinical practice, particularly in stereotactic and functional neurosurgery, although clinical applications are still lagging behind the atlas content progress. Atlas functionality also has been relatively neglected until recently, as the management of brain data explosion requires powerful tools. We suggest that the future human brain atlas-related research and development activities shall be founded on and benefit from a standard framework containing the core virtual brain model cum the brain atlas platform general architecture.
\end{abstract}

Keywords Human brain atlas $\cdot$ Brain atlas evolution $\cdot$ Brain atlas generations $\cdot$ Brain atlas review $\cdot$ Brain atlas platforms

\section{Introduction}

We witness in recent years a tremendous explosion of human brain atlas projects with various goals, scopes, and sizes, as addressed, for instance, in (Amunts et al. 2014; Frackowiak and Markram 2015; Nowinski 2017a; Hess et al. 2018). This explosion is propelled by brain-related big and well-funded initiatives and projects, including The BRAIN Initiative (Brain Research through Advancing Innovate Neurotechnologies) (BRAIN Working Group 2014) to develop technology to catalyze neuroscience discovery (Jorgenson et al. 2015); The

Wieslaw L. Nowinski

w.nowinski@uksw.edu.pl; https://www.WieslawNowinski.com

1 John Paul II Center for Virtual Anatomy and Surgical Simulation, University of Cardinal Stefan Wyszynski, Woycickiego 1/3, Block 12, room 1220, 01-938 Warsaw, Poland
Human Brain Project to create a research infrastructure to decode the human brain, reconstruct the brain's multiscale organization, and create brain-inspired information technology (Amunts et al. 2016); The Human Connectome Project to map structural and functional connections in the brain in order to study the relationship between brain circuits and behavior (Van Essen et al. 2013); The Allen Brain Atlas to map gene expression (Sunkin et al. 2013); The Big Brain to obtain ultrahigh resolution neuroimages (Amunts et al. 2013); The Blue Brain Project to simulate neocortical micro-circuitry (Markram et al. 2015); The CONNECT project to combine macro- and micro-structure (Assaf et al. 2013); the Brainnetome project to understand the brain and its disorders, develop methods of brain network analysis at different scales, and create the brainnetome atlas (Jiang 2013); the Chinese Color Nest Project to study human connectomics across the life span (Zuo et al. 2017); and the Japanese Brain/MINDS (Brain Mapping by Integrating Neurotechnologies for 
Disease Studies) project to further understand the human brain and neuropsychiatric disorders through "translatable" biomarkers (Sadato et al. 2019). Therefore, with the new acquisition techniques introduced and big data acquired, sophisticated applications and tools developed, and novel concepts proposed, this explosion dynamically changes over time the concept, role, and understanding of a human brain atlas. Consequently, it is believed that the use of big digital science to neuroscience will create new avenues for the development of a modern human cerebral cartography (Frackowiak and Markram 2015). Two major forces driving this brain atlas development these are human curiosity along with scientificbased interest empowered by the developments in brain mapping technology and computing, and clinical needs urged by the growing cost of brain disorders and society aging.

The purpose of this state-of-the-art review is to attempt capturing the evolution of human brain atlases as well as to demonstrate the immense breadth of the ongoing work and its tremendous potential. We track this process of evolution over time, identify its numerous directions and categorize them, try to distinguish brain atlas generations, and capture the present state. Typically this evolution is considered in terms of atlas content, particularly, in research applications. However, the usefulness of human brain atlases depends not only on the atlas content but also on the functionality enabling and supporting various atlas-based applications as well as atlas availability. Therefore, our goal here is to take a wider perspective and address the human brain atlas development in terms of four major categories: (1) atlas content; (2) atlas applications in various areas; (3) functionality enabling and facilitating atlas use; and (4) availability in terms of access, media, and platforms enabling the atlas delivery to its user.

The rest of the paper is organized as follows. The brain atlas evolution is reviewed in Sect. 2 in terms of atlas content (categorized into 8 main groups from 23 directions for the new electronic brain atlases taking into account diverse criteria), applications, functionality, and availability. In Sect. 3 four generations of brain atlases are distinguished and the process of atlas evolution is captured diagrammatically, followed in Sect. 4 by the discussion along with some suggested future directions.

\section{Evolution of Human Brain Atlases}

We track below the evolution of human brain atlases in terms of content, applications, functionality, and availability.

\section{Evolution of Brain Atlas Content}

The brain atlas content is the richest and most dynamic category whose development proceeds along multiple divisions, including postmortem versus in vivo data, whole brain versus specific cerebral regions, structure versus function, single data acquisition modality versus multi-modal data, single brain specimen and individual features versus a population of specimens and/or aspects, in health versus diseased, static print versus dynamic digital, single atlas versus multi-atlases, slow versus fast dynamic, and mono scale versus multi-scale, among others.

The initial development of cerebral cortical maps was carried out predominantly in a single direction, meaning studying the cortical parcellation. Several early maps of the parcellated cerebral cortex were created in the first three decades of the 20th century by Campbell (1905), Brodmann (1909), Vogt and Vogt (1919), Flechsig (1920), and Von Economo and Koskinas (1925). These first, postmortem, hand-drawn cortical maps were produced for a single modality, cytoarchitectonics (Brodmann 1909; Von Economo and Koskinas 1925) or myeloarchitectonics (Vogt and Vogt 1919; Flechsig 1920), and they varied in terms of the number of the parcellated cortical areas. Namely, in the neocortex Campbell (1905) identified 14 areas, Brodmann (1909) 44 areas, Von Economo and Koskinas (1925) 54 areas, and Vogt and Vogt (1919) 185 areas. This process of cortical parcellation pioneered by Brodmann and the other early brain mappers a century ago continues until the present time being extended (1) from schematic two-dimensional (2D) single brain-derived surface drawings to multi-modal, populationbased probabilistic three-dimensional (3D) maps (Glasser et al. 2016) facilitating to study intersubject variability; and (2) from pure visual inspection of the examined material to the application of robust, objective and observer-independent cortical parcellation rules based on quantitative criteria and statistical measures (Amunts and Zilles 2015), additionally enhanced by employing in vivo mapping with high-field magnetic resonance imaging (Geyer et al. 2011).

The need in neurosurgery to localize cerebral structures in the pre-tomographic imaging era caused the creation of stereotactic brain atlases (a review of print and electronic stereotactic atlases of the human brain is presented by Alho et al., (2011)). These initially print atlases represented a big step forward in atlas development both in terms of atlas content and concept. In the 1950th stereotactic brain atlases were produced by Speigel and Wycis (1952), Talairach et al. (1957), and Schaltenbrand and Bailey (1959). This development was continued by Andrew and Watkins (1969), Van Buren and Borke (1972), Schaltenbrand and Wahren (1977), Afshar et al. (1978), and Talairach and Tournoux (1988, 1993).

The major content-wise progress was made in four main directions: (1) from a few maps capturing the state-of-the-art about the brain to brain atlases applicable clinically; (2) from cerebral cortical maps to atlases of the whole brain (or its specific parts, including subcortical structures, cerebellum, and brainstem); (3) from a single specimen to multiple specimens with marked anatomic variability, although without any probabilistic maps yet 
(e.g., Schaltenbrand and Wahren (1977) used 111 brain specimens to create their atlas); and (4) integrating structure with function (neuroelectrophysiologic stimulation) like in the Schaltenbrand and Wahren atlas.

Besides stereotactic, some other print atlases were published for neuroradiology, neurosurgery, neuroscience, and medical education and training, among others, a brain atlas for computed tomography (Takayoshi and Hirano 1978), an atlas of the hippocampus (Duvernoy 1988), an atlas of brain function (Orrison 1995), an atlas of the brain stem and cerebellum with surface anatomy and vascularization (Duvernoy 1995), an atlas of morphology and functional neuroanatomy (Scarabino et al. 2006), an atlas of the brain stem and cerebellum with 9.4T images of 40-60 micron resolution (Naidich et al. 2009), and the Netter's atlas of neuroscience (Felten et al, 2015). In particular, some stereo brain atlases are created as a $3 \mathrm{D}$ depth perception is essential in neurosurgical routine. Bassett (1952) produced a stereoscopic atlas of human anatomy with stereo cadaveric images of the central nervous system, head, and neck. Poletti (1985) built a stereo atlas of operative microneurosurgery with stereo photographs taken intraoperatively. Kraus and Bailey (1994) created a stereo atlas of microsurgical neuroanatomy with successive surgical steps recorded photographically; moreover, a binocular viewer is attached to the atlas to perceive depth.

A natural step forward in brain atlasing was the development of computerized electronic brain atlases aiming to overcome limitations of their print counterparts, such as static content, image plate sparseness, lack or limited functionality, cumbersome use, lack of interactivity, and difficulty in the mapping of the atlas content into an individual brain scan. These efforts have been headed at least in five directions: (1) direct digitization of the existing print atlases (Kall et al. 1985); (2) creation of bi-media atlases with both print and digital content (Zhang et al. 2003; Mai et al. 2004; Morel 2007); (3) 3D extension of the existing print atlases (Yoshida 1987; St-Jean et al. 1998); (4) creation of improved atlases derived from the print content by postprocessing, enhancements, and extensions (Nowinski et al. 1997a; Sudhyadhom et al. 2012); and (5) development of new electronic atlases (such as early ones, e.g., by Bohm et al. (1983) and Greitz et al. (1991) constructed from digitized crysection photographs, and many more created recently, as reviewed below). Note that the first two directions require no change in the original atlas content.

To our best knowledge the first computer program with digitized (and scalable) stereotactic atlases was developed by Bertrand et al. (1974). A digital version of the Schaltenbrand and Wahren atlas resident in a computer was created by Kall et al. (1985). Several groups developed electronic versions of the Schaltenbrand and Bailey atlas, namely, Yoshida (1987) built a 3D atlas by interpolating print plates, a 3D volumetric model of subcortical structures was produced by Kazarnovskaya et al. (1991), and Sudhyadhom et al. (2012) created a deformable 3D atlas for deep brain stimulation surgery by employing smoothing to reduce artifacts inherent in the print version. Similarly, digital versions of the Schaltenbrand and Wahren atlas were built and incorporated into atlas-aided software systems for stereotactic and functional neurosurgery by Sramka et al. (1997) and StJean et al. (1998), who developed a deformable volumetric version of the atlas.

We created a multi-brain atlas database with about 1000 structures and 400 sulcal patterns embedded into a neuroimaging system (Nowinski et al. 1997a) based on the content of four complementary classic Thieme brain atlases: Schaltenbrand and Wahren, Talairach and Tournoux (1988), Talairach and Tournoux (1993), and Ono et al. (1990) ${ }^{1}$. The original atlases were highly processed, manually edited, enhanced, fully segmented and labeled, extended including into 3D, and mutually spatially co-registered. Various content representations were created, including color-coded, contour (closed for structures and open for sulcal patterns), and polygonal. They facilitate atlas use and navigation and, particularly, the unique (color-coded or contour) representation enables automated labeling. A high-quality content along with a proposed method of atlas use (Nowinski 1998) caused the integration of this multi-brain atlas database into a majority of surgical workstations for clinical use (Nowinski 2009).

In addition, new dedicated neurosurgical atlases have been developed in the second decade of this century and they are discussed below.

Neuroeducation has driven the extension of the brain atlas content from 2D to 3D. The three-dimensional effect has been achieved by various techniques ranging from a simple form of virtual reality (VR) through QuickTime VR technology (Kling-Petersen and Rydmark 1997) to visualization of truly 3D representations by employing volume rendering of volumetric data (Hoehne et al. 1992) and surface rendering of geometric (polygonal) models (Nowinski et al. 2011b). The latter approach provides fast rendering of geometric models created with subpixel resolution, e.g., as small as $1 / 10$ th of the pixel size (Nowinski et al. 2012a). An overview of methods for $3 \mathrm{D}$ visualization of neuroanatomical image data and reconstruction of neuronal structures in brain atlases is presented by Maye et al. (2006).

Atlas-assisted neuroeducation, training, and simulation have greatly benefitted from the Visible Human Project (VHP) comprising the most complete volumetric data of human anatomy, including cryosection photographs, computed tomography and magnetic resonance images of American male and female specimens (Spitzer et al. 1996). The VHP provides excellent source material for the creation of brain atlases and maps, for instance by Drury and Van Essen (1997) and Juanes et al. (2012). The VHP additionally sparked

\footnotetext{
1 Note that we were the only research group that received rights from the publisher to use these atlases.
} 
other projects, including Chinese VHP and Korean VHP, resulting in the construction of new atlases (Zhang et al. 2003; Li et al. 2014) along with suitable tools for sectional and surface anatomy navigation as well as virtual dissection and endoscopy simulation (Chung and Park 2007).

Tremendous advancements in imaging, brain mapping, and computing propelled the development of new human electronic brain atlases. Various criteria can be employed to identify and systemize multiple directions in the content evolution of new atlases, including parcellation, modality, plurality, quality, ab/normality, lifespan, extendibility, ethnicity, spatial and temporal scales, integration, transformation, techniques of creation, and combination of them. We determine 23 directions and categorize them into eight (seven main and one combined) groups of brain atlas content development. Then, by taking into account this categorization, a brain atlas instant can be considered as an element in a seven-dimensional brain atlas space. These groups along with their component directions are as follows:

1. Scope (content extent)

a. From cerebral parts (e.g., the basal ganglia (Yelnik et al. 2007), thalamus and basal ganglia (Morel 2007), thalamus (Krauth et al. 2010), and deep brain structures (Lemaire et al. 2019)) to the whole brain (Kikinis et al. 1996; Hoehne 2001; Tzourio-Mazoyer et al, 2002; Nowinski et al. 2011b);

b. From structural neuroanatomy (Rohlfing et al. 2010; Mandal et al. 2012; Nowinski and Chua 2014) to vascular neuroanatomy (Nowinski et al. 2009b; 2011a; Huck et al. 2019) to connectional neuroanatomy (Mori et al. 2005; Nowinski et al. 2012b; Van Essen 2013; Van Essen et al. 2013; Baker et al. 2018; Briggs et al. 2018) to gene expression (Sunkin et al. 2013) including gene expression in brain development (Kanton et al. 2019);

c. From brain to head (Tiede et al. 1996; Chen et al. 2018), and to head and neck (Nowinski 2017b);

d. From structure to function, including functional atlases (Minoshima et al. 1994; Zhao et al. 2017; Haegelen et al. 2018; Varoquaux et al. 2018; Lehman et al. 2020), integrated anatomic-functional atlases (Nowinski 2004; Nowinski et al. 2010), and functional connectivity atlases (Craddock et al. 2012; James et al. 2016).

2. Parcellation

Use of diverse, often multiple parcellation criteria, from classic cytoarchitecture, myeloarchitecture and gross anatomy to fMRI, chemoarchitecture (Yelnik et al. 2007), vascular territories (Nowinski et al. 2006), anatomic connectivity (Mori et al. 2005), functional connectivity (Arsiwalla et al. 2015), anatomic-functional connectivity (Fan et al. 2016), (multi)receptor architecture (Amunts et al. 2010), and/or multiplicity of them (Van Essen 2013; Glasser et al. 2016), among others.

3. Modality

a. From postmortem to in vivo data (Lehmann et al. 1991; Nowinski et al. 2015a; Dickie et al. 2017; Oishi et al. 2019);

b. Integrating postmortem - in vivo data (Nowinski et al. 1997b; 2002b; Yelnik et al. 2007; Cho et al. 2008; Amunts et al. 2014);

c. Increased teslage, from 1.5T (Tesla) (Hoehne 2001) to 3T (Nowinski et al. 2009b; Rohlfing et al. 2010) to 7T (Cho et al. 2008; Nowinski et al. 2015a; Saygin et al. 2017; Huck et al. 2019; Liu et al. 2020) to 9.4T (Yushkevich et al. 2009);

d. From image to non-image data, transforming into brain atlases non-image data, such as stimulating electrode geometry (Nowinski et al. 2003) and neurologic parameters (Nowinski et al. 2014a).

4. Plurality

a. Specimen-related: from a single specimen to population atlases for cerebral parts (such as the cerebellar nuclei (Dimitrova et al. 2006), insula (Faillenot et al. 2017), cortical structures (Shattuck et al. 2008), and cerebral arteries (Dunås et al. 2017) to the whole human brain (Mazziotta et al. 1995; 2001; Thompson et al. 2000);

b. Variant-related: from a single variant to a collection of variants, for instance, the cerebrovascular variants (Nowinski et al. 2009a);

c. Modality-related: from uni-modal to multi-modal atlases with the use of multi-modal complementary data (e.g., Johnson and Becker 1999; Toga et al. 2006; Nowinski et al. 2010; Hawrylycz et al. 2012; Ding et al. 2016);

d. Channel-related: e.g., with anatomy, diffusion, and tissue channels (Rohlfing et al. 2010);

e. Atlas-related: from a single atlas to arrays of fully parcellated atlases or mega multi-atlases ( $\mathrm{Wu}$ et al. 2016).

5. Scale

a. Spatial scale, from macro- to meso- to micro- to nanoscales along with integrating atlas data across multiple spatial scales (Assaf et al. 2013; Ding et al. 2016; Ecker et al. 2017);

b. Temporal scale covering atlases from development (Kanton et al. 2019) to lifespan including age-matched atlases to accommodate age-dependent anatomical changes ranging from pediatric to geriatric populations (Wu et al. 2016; Zuo et al. 2017; Zhang et al. 2018; Oishi et al. 2019); 
c. Integrating spatio-temporal scales (Sunkin et al. 2013; Bozek et al. 2018).

6. Ethnicity

Ethnic-specific atlases, for instance, for Chinese (Zhang et al. 2003), Korean (Cho et al. 2008), and Caucasian (Nowinski 2017b) specimens.

7. Abnormality

From normal to disease-specific atlases for various brain disorders, for instance, Alzheimer's disease (Thompson et al. 2001), dementia (Mega et al. 2005), and stroke (Nowinski et al. 2014a; de Haan and Karnath 2017).

8. Multiple (combined) groups

a. Population multi-modal atlases (Iglesias et al. 2018);

b. Population functional maps and atlases (Nowinski et al. 2003; Nowinski 2009; Breshears et al. 2015);

c. Population spatio-temporal atlases, for instance, of brain development (Kuklisova-Murgasova, et al. 2011);

d. Population ethnic atlases and templates, for instance, Chinese brain atlas (Tang et al. 2010), Indian brain template (Bhalerao et al. 2018) and atlas (Sivaswamy et al. 2019), Korean brain template (Lee et al. 2005), and French brain template (Lalys et al. 2010).

We witness recently an enormous development of population-based brain atlases both in health and disease. Population-based structural atlases have been built for the whole brain (Liang et al. 2015; Wu et al. 2016) and its specific regions, such as the cortical areas (Shattuck et al. 2008; Glasser et al. 2016), cerebellum (Diedrichsen et al. 2009), brainstem (Meola et al. 2016), subcortical nuclei (Pauli et al. 2018), thalamic nuclei (Iglesias et al. 2018; Najdenovska et al. 2018), insula (Faillenot et al. 2017), some gyri including the parietal lobe gyri (Wild et al. 2017) and the inferior frontal gyrus (Hammers et al. 2007), and venous cerebrovasculature (Huck et al. 2019).

More advanced atlases have been developed in terms of population (Liang et al. 2015), specimen age range span (Wu et al. 2016; Zhang et al. 2018), and age appropriateness (Fonov et al. 2011). For instance, the atlas of Chinese adults contains a large number of 2020 specimens whose age spans from 20 to 75 years at a 5-year interval (Liang et al. 2015). The longitudinal atlas for normative brain development and aging spans the age range of 1-83 years, while the quantitative susceptibility mapping used for its creation may facilitate the estimation of age-related iron changes in deep gray matter nuclei and myelin changes in white matter (Zhang et al. 2018). A mega multi-atlas (Wu et al. 2016) constitutes an inventory of 90 brain atlases with the specimens ranging from 4 to 82 years of age. Several agedependent brain atlases have been built also for children $(\mathrm{Ou}$ et al. 2017; Bozek et al. 2018) and fetuses, such as a dynamic
4D (four-dimensional) probabilistic atlas of the developing brain (Kuklisova-Murgasova, et al. 2011). The baby brain atlases developed for specimens younger than 12 months old (for the fetus, neonate, and infant) are reviewed by Oishi et al. (2019).

Besides probabilistic structural atlases also a variety of probabilistic connectional atlases (Meola et al. 2016; Figley et al. 2017; Yeh et al. 2018; Chenot et al. 2019), functional maps and atlases (Nowinski et al. 2003; Nowinski 2009; Breshears et al. 2015), and vascular atlases (Dunås et al. 2017; Bernier et al. 2018; Mouches and Forkert 2019) have been created.

Developments in mapping the microscopical organization of the brain along with the progress in nanoscience (Alivisatos et al. 2013) enable the construction of brain maps and atlases across spatial scales extending from macro to meso to micro to nano. Examples include the BigBrain with 20-micrometer resolution (Amunts et al. 2013), a comprehensive cellular-resolution (of $1 \mu \mathrm{m} / \mathrm{pixel}$ ) brain atlas linking macroscopic anatomical and microscopic cytoarchitectural parcellations (Ding et al. 2016), the Brain Activity Map as the functional connectome to elucidate emergent levels of neural circuit function (Alivisatos et al. 2012), a temporal cell atlas of gene expression in brain development (Kanton et al. 2019), a genomics brain atlas (Sunkin et al. 2013), a proteomic brain atlas (McKetney et al. 2019), an atlas of serotonin (Beliveau et al. 2017), and an atlas of brain transcriptome (Hawrylycz et al. 2012). In particular, identifying the different brain cell types to determine their roles in health and disease is of great importance and it is established as one of the six goals of the BRAIN Initiative (BRAIN Working Group 2014). Toward achieving this goal a whole-brain cell atlas is under development by Ecker et al. (2017) that integrates molecular, anatomical, and physiological annotations of neuronal cell types for a comprehensive characterization of cell types, their distributions, and patterns of connectivity.

\section{Evolution of Brain Atlas Applications}

The rationale of creating the early cortical maps, the result of human curiosity, was to represent the knowledge of new discoveries about the human brain. The brain knowledge capturing, aggregation, and representation by means of human brain atlases has been the first application of the atlases, and this central role remains until the present. Research has been the dominant application of human brain atlases (Roland and Zilles 1994) employed as tools for analysis of brain structure and function (Hess et al. 2018), means to integrate neuroscience research data from healthy and diseased brains to increase data sharing and reusing (Bjerke et al. 2018), and a potential tool suitable for image structurization through atlas-based image parcellation to utilize a vast amount of imaging information available in medical record systems, such as the PACS (picture archiving and communication system) (Mori et al. 2013). Moreover, disease-specific atlases, such as (Thompson et al. 2001; Mega et al. 2005; de 
Haan and Karnath 2017) facilitate quantification of brain structural deficits in epilepsy, depression, schizophrenia, Alzheimer's disease, bipolar disorders, autism and others disorders as discussed by Toga and Thompson (2005).

Human brain atlases are also useful beyond research in medical education and clinical applications. Stereotactic and functional neurosurgery was the first, major clinical application of brain atlases. We observe that every two decades mark major progress in this field. The first print atlases were created in the 1950th, the first digitized brain atlas was developed in the 1970th (Bertrand et al. 1974), and the acceptance of our electronic brain atlases to clinical practice by the community (and 13 surgical companies) started in the 1990th (Nowinski 2009). Initially, a digital atlas was used off-line for referencing while being placed beside the displayed patient-specific scan. In this way, for instance, The Electronic Clinical Brain Atlas (Nowinski et al. 1997b) had been employed next to a surgical workstation to plan neurosurgery before our brain atlas database was directly integrated with surgical workstations, such as the StealthStation (Nowinski 2009). In the second decade of this century several novel, neurosurgery-dedicated atlases have been developed for electrode placement in deep brain stimulation (Sadikot et al. 2011; Dergachyova et al. 2018; Haegelen et al. 2018; Nowacki et al. 2018).

In the pre-tomographic era, stereotactic brain atlases were useful to localize deep stereotactic targets. The introduction of diagnostic imaging has not eliminated brain atlases but rather changed their role and function (Nowinski 2009). Namely firstly, a high atlas parcellation, typically greater than that of a scan, allows the individualized atlas to facilitate targeting. Secondly, extensive atlas features in combination with its ease of use and precision facilitate neurosurgery planning and provide intraoperative support, like those available in The Cerefy Clinical Brain Atlas: Extended Edition with Surgery Planning and Intraoperative Support (Nowinski et al. 2005a). Thirdly, several new dedicated brain atlases have been created that are derived from various modalities including histology (Chakravarty et al. 2006), electrophysiology (Finnis et al. 2003; Nowinski et al. 2003), and multi-modalities (Yelnik et al. 2007; Nowinski et al. 2010; Haegelen et al. 2018).

Other examples of atlas use in neurosurgery include a digital brain atlas for surgical planning (Kikinis et al. 1996), an Internet portal for stereotactic and functional neurosurgery shifting the paradigm in atlas building from manufacturercentric (dependent) to neurosurgical community-centric (Nowinski et al. 2002a), and a practical 3D atlas for a preoperative white matter-specific planning of subcortical trajectories (Jennings et al. 2018).

Several neuroeducational atlases were created in the 1990th, the Decade of the Brain, including BrainStorm (Dev et al. 1992), Digital Anatomist (Sundsten et al. 1994), A.D.A.M. (A.D.A.M 1996), Microvascular Atlas of the Head and Neck (Bayer 1996), The BRAIN project (Kling-Petersen and Rydmark 1997), and The Electronic Clinical Brain Atlas (Nowinski et al. 1997b).

These initial efforts were followed by the development of more advanced atlases in terms of content and functionality, such as Voxel-man (Hoehne 2001), The Cerefy Atlas of Brain Anatomy (Nowinski et al. 2002b), Primal's Interactive Head \& Neck (Berkovitz et al. 2003), The Cerefy Clinical Brain Atlas (Nowinski and Thirunavuukarasuu 2004), The Cerefy Atlas of Cerebral Vasculature (Nowinski et al. 2009b), The Human Brain in 1492 Pieces (Nowinski et al. 2011b), The Human Brain in 1969 Pieces: Structure, Vasculature, Tracts, Cranial Nerves, Systems, Head Muscles, and Glands (Nowinski and Chua 2014), The Human Brain, Head and Neck in 2953 Pieces (Nowinski et al. 2015a), and the Human Anatomy Atlas (Visible Body n.d.). In addition, individualized atlases that parcellate and annotate brain scans are useful for the creation of teaching files of brain anatomy and function (Oishi et al. 2019).

The brain atlases also play a role in training and simulation, e.g., in neurosurgery (Serra et al. 1997) and radiotherapy (Roniotis et al. 2012).

Human brain mapping in research and clinical practice is another major area of brain atlas employment. Digital brain atlases are exploited here to provide the underlying neuroanatomy and to automatically label activation loci in functional images with cortical areas and stereotactic coordinates. Application examples include the BrainMap (Lancaster et al. 2000) and the Brain Atlas for Functional Imaging (Nowinski et al. 2000b). Both these tools employ digital Brodmann's areas (derived from the Talairach and Tournoux (1988) brain atlas) that are hidden in the BrainMap while explicitly available and displayed to the user in the Brain Atlas for Functional Imaging. Brodmann's areas, despite being one century old and originally limited to two views on the visible part of the cortical surface only, are still today applicable references in human brain mapping to register functional activations to the underlying anatomy (Amunts and Zilles 2015). ). Because of well-known limitations of the Talairach and Tournoux atlas (see, e.g., (Nowinski and Thirunavuukarasuu, 2009)) in order to improve labeling of functional foci a dedicated AAL (Automated Anatomical Labeling) atlas was developed from a T1-weighted scan with 45 anatomical volumes of interest in each hemisphere (Tzourio-Mazoyer et al, 2002).

Nuclear medicine, such as SPECT (single-photon emission computed tomography) and PET (positron emission tomography), produces images of relatively poor spatial resolution, which makes it difficult to relate the functional information contained there to the corresponding underlying neuroanatomy. In order to enhance the accuracy and consistency of the anatomic interpretation of PET functional brain images, Minoshima et al. (1994) constructed a PET stereotactic brain atlas from a high-resolution [18F]FDG (fluorodeoxyglucose) images of a normal volunteer. In addition, to assist in the interpretation of SPECT scans of the brain, a 3D 
neuroanatomical atlas was created from an MRI scan of a normal, healthy volunteer by Lehmann et al. (1991).

Human brain atlases have potential in stroke management for prediction, diagnosis, and treatment (Nowinski 2020). The atlases of anatomy and blood supply territories support decision making in thrombolysis and provide a quantitative assessment of the infarct and penumbra (Nowinski et al. 2006). These two atlases also facilitate rapid and automatic detection, localization, and classification of ischemic and hemorrhagic lesions in the emergency room (Nowinski 2020). The probabilistic stroke atlas, created by the integration of brain scans with textual neurologic parameters of previously managed stroke patients, enables prediction of stroke outcomes (Nowinski et al. 2014a).

We have also developed atlas-based applications in several other areas, including neuroradiology, neurology, psychology, psychiatry, and proposed new solutions in some niche applications, such as atlas-guided do-it-yourself neurosurgery suitable for patients (Nowinski 2009) and an atlas-enhanced operating room for the future (Benabid and Nowinski 2003).

In neurology, the $3 D$ Atlas of Neurologic Disorders (Nowinski et al. 2014b) facilitates the understanding of neurologic deficits resulting from brain damage. The atlas bridges neuroanatomy, neuroradiology, and neurology (Nowinski and Chua 2013a). It serves as an educational means for neurology students and residents as well as a reference for neurologists. This atlas is also a potentially useful tool for psychologists, and particularly neuropsychologists, to communicate with patients.

The Cerefy Neuroradiology Atlas (Nowinski and Belov 2003) available over the Internet contains a fully segmented and labeled anatomic brain atlas. It provides functions for a rapid atlas-to-scan registration, interactive structure labeling and annotating, and mensuration. To our best knowledge, this is the first online, publicly available atlas-based application for neuroradiology. In general, brain atlases have a still unexploited potential in neuroradiology. For instance, in (Nowinski 2016) nine various scenarios of atlas use in neuroradiology were discussed based on the earlier developed working prototypes ranging from image interpretation to reporting to dealing with data explosion and to communication (for both doctor-todoctor and doctor-to-patient).

In psychiatry, we employed a brain atlas to automatically generate anatomic volumes of interest for subsequent analysis in a population of schizophrenic patients and controls to study the passivity phenomenon (Sim et al. 2009).

\section{Development of Atlas Functionality}

The early bare brain maps and atlases had no or a very limited supporting functionality. Therefore, certain early print stereotactic brain atlases, besides providing standard anatomical indices (along with some accompanying textual description), were placed in a stereotactic coordinate system enabling localization and referencing. Moreover, certain atlases were equipped with transparent overlays with structure annotations over the brain plates to facilitate structure delineation and identification. Conceptually, this simple functionality already signaled the necessity of equipping brain atlases with suitable tools enabling their clinical applications. This necessity in the pre-digital era was clearly expressed by a popular practice performed in the operating room of generating resized (individualized) brain atlas plates by means of an overhead projector and drawing a planned stereotactic trajectory directly on the displayed projection.

The need of generating individualized atlases in neurosurgery was met in the first computer program with digitized stereotactic atlases developed by Bertrand et al. (1974) that provided 1D (one-dimensional) atlas scaling along the intercommissural distance. This solution was followed by a $3 \mathrm{D}$ piece-wise linear (Nowinski et al. 2000a) and non-linear (Ganser et al. 2004) brain atlas warping. The requirements from stereotactic and functional neurosurgery have been an initial major driving force behind the brain atlas development, both in terms of content (as discussed above) and functionality. Specific atlas-related tools have been proposed for preoperative planning, intra-operative support, and postoperative assessment (Nowinski 2001a).

Pre-operatively, the atlas facilitates the target and trajectory planning to avoid some critical structures (such as the optic tract), and provides the list of trajectory-intersected structures. In order to increase both the quality of planning and the surgeon's confidence, multiple complementary atlases are employed (Nowinski et al. 2000a; 2010). In general, the atlas facilitates the planning of the access corridor to any target structure by determining all the structures encountered along the selected corridor and those neighboring it, allowing the neurosurgeon to assess various potential corridors in the process of decision making. Intra-operatively, the atlas provides the actual structure where the tip of the electrode is located, the list of structures already intersected by the electrode, distances to critical structures, and the surrounding anatomic and vascular context (Nowinski et al. 2010). Additionally, the probabilistic functional atlas makes the targeting more accurate by determining the best location within the whole target structure (Nowinski et al. 2003; 2005b). Post-operatively, the atlas facilitates to analyze the correctness of placement of a stimulating electrode or a permanent lesion.

The first (to our best knowledge) collaborative use and construction of a brain atlas over the Internet by the neurosurgical community was offered in the portal for stereotactic and functional neurosurgery supporting a probabilistic functional atlas (Nowinski et al. 2002a). This atlas is calculated from neuroelectrophysiologic and neuroimaging patient-specific data acquired during functional neurosurgical procedures 
(Nowinski et al. 2003). The portal supports the atlas with the functionality enabling data uploading to the central database or downloading locally in order to combine them with the neurosurgeon's own data, followed by the calculation of the individualized probabilistic functional atlas and surgery planning. The atlas is displayed graphically in $2 \mathrm{D}, 3 \mathrm{D}$, and as a probability distribution histogram along with the data tree (including patients, electrodes, contacts, and coordinates) in a text format.

The development of atlas functionality has also been driven by the needs of the human brain mapping community, mainly for the integration of structural and functional, and, generally, multi-modal images in the same stereotactic space as well as for atlas-assisted automatic labeling of activation loci in functional images with cortical areas and stereotactic coordinates. The SPM anatomy toolbox (Eickhoff et al. 2005) is an example of an image integration tool that enables the combination of probabilistic cytoarchitectonic maps and results of functional imaging studies. Another data integration tool is the Neuroinformatics Platform within the Human Brain Project (Bjerke et al. 2018). Examples of labeling tools are the BrainMap (Lancaster et al. 2000) and the Brain Atlas for Functional Imaging (Nowinski et al. 2000b). The BrainMap assigns a label of the cortical area closest to the examined activation locus. This process is blind to the user as the brain atlas employed is hidden from display. In the Brain Atlas for Functional Imaging the parcellated, labeled, and color-coded cortical areas are explicitly available and displayed to the user, who has full control over the process of activation loci labeling and is able to edit their positions if needed. This atlas processes functional images through a locus-driven analysis (Nowinski and Thirunavuukarasuu 2003). The activation loci in functional images are extracted automatically by thresholding with the option of interactive editing. Then, the atlas of anatomy extended with Brodmann's areas is employed for labeling of the activation loci with the names of cerebral structures, Brodmann's areas, and stereotactic coordinates. The activation loci are marked on the images with the superimposed atlas, and the list of all labeled loci along with their values on the anatomic and functional images is provided to the user.

Neuroinformatics tools and repositories also have been developed to store various and heterogeneous results of analyses. For instance, NeuroVault.org stores these results in a form of statistical maps, parcellations, and atlases (Gorgolewski et al. 2016); and BALSA is a database of the brain analysis library of spatial maps and atlases (Van Essen et al. 2017).

Construction of population atlases as well as atlas-assisted neuroimage processing and analysis in any application requires atlas-to-scan (or scan-to-atlas) registration. Pioneering work on atlas-to-scan elastic registration was done by Bajcsy et al. (1983) and Gee et al. (1993). Brain image registration algorithms are evaluated, for instance, by Klein et al. (2009) and $\mathrm{Ou}$ et al. (2014). Image registration is also employed for multi-modal atlas construction and atlas-guided segmentation of brain images. Automatic segmentation of brain images, in particular, is of great importance and it can be performed through atlas-to-scan registration, as the individualized atlas segments and labels the underlying neuroanatomy. The majority of methods are for the segmentation of structural neuroanatomy, though some approaches are developed to provide atlas-based processing of connectional neuroanatomy (Labra et al. 2017) and cerebrovascular anatomy (Passat et al. 2006; Dunås et al. 2016). As multi-atlases are more powerful than single atlases, numerous approaches have been developed for multi-atlas based brain segmentation (Aljabar et al. 2009; Artaechevarria et al. 2009; Lötjönen et al. 2010; Wu et al. 2016; Zaffino et al. 2018; Li et al. 2019).

In neuroeducation a typical atlas-related functionality includes labeling, searching, and atlas display and manipulation. Beyond typical operations, some atlases provide more sophisticated operations, such as advanced labeling with vessel diameters (Nowinski et al. 2011b) and pathology description (Nowinski et al. 2014b) as well as quantification, such as geometric measurements (Nowinski et al. 2015a).

The atlas also enables automatic testing suitable for both self-testing and classroom testing. A testing module for atlasenabled evaluation of brain knowledge in neuroeducation was designed and incorporated into The Cerefy Atlas of Brain Anatomy (Nowinski et al. 2002b), and the corresponding method presented in (Nowinski et al. 2009c). The module allows the instructor to set the testing parameters first, such as the scope of the tested knowledge, scoring points, and the number of attempts. The items (structures) in the index are consecutively numbered forming a list. A random generator selects randomly items from the list while avoiding repetition. There are two types of queries "Where is?" and "What is?" to test location and naming of cerebral structures, respectively. When the name of the selected item is highlighted in the index, the student is tested against "Where is?" aiming to point to the selected structure in the atlas (image or model). When the selected structure is highlighted in the atlas, the student is tested against "What is?" aiming to indicate the name of this structure in the index. After all the structures have randomly been selected, the module provides the total score and the time spent to perform the test. Note that for the same scope of a tested brain knowledge the queries, which are randomly generated, are different each time avoiding this way the situation that the student copies someone else's answers or memorizes them.

Some other examples of application-specific functionality in our atlas-based solutions include brain scan interpretation in neuroradiology (Nowinski and Belov 2003), segmentation and labeling of pathological neuroimages (Nowinski and Belov 2005), automatic generation of atlas-derived regions and volumes of interest (VOI/ROI) for fast comparison of the left and right cerebral hemispheres to detect pathology 
(Nowinski 2020) and for statistical analysis in populations (Sim et al. 2009), aggregation of image and clinical brain data (Nowinski et al. 2014a), dealing with data explosion (Nowinski 2016), radiology reporting (Nowinski 2016), and brain knowledge communication (for both doctor-to-doctor and doctor-to-patient) (Nowinski 2016).

The abovementioned operations and tools are incorporated into the atlasing software platforms, mostly to enable and enhance the atlas use. However, there exist numerous stand-alone tools suitable for atlas creation and use that are not incorporated directly into the created brain atlas platforms, such as FreeSurfer, a suite of tools for a cortical surface generation and quantification of functional, connectional and structural properties of the human brain (Fischl 2012) extended recently with the probabilistic atlas of the thalamic nuclei (Iglesias et al. 2018); SPM for a neuroanatomical variability assessment (Ashburner 2009); FSL, a comprehensive library of analysis tools for functional, structural, and diffusion MRI brain imaging data (Jenkinson et al. 2012); the Medical Imaging Interaction Toolkit (MITK) integrating two other powerful toolkits, the Visualization Toolkit (VTK) and the Insight Toolkit (ITK) (Wolf et al. 2005); and the Vascular Editor to create and edit vascular and, generally, tubular-like such as cranial nerve networks (Marchenko et al. 2010). Our experience shows that the tools directly integrated with the atlas have proved their value allowing any new atlas modules to be created and edited within the already existing neural context (Nowinski et al. 2012a; b).

Recently, a new generation of methods, tools, repositories, and neurotechnologies is planned or already under development. For instance, intensive technology development and validation is outlined under the BRAIN Initiative (BRAIN Working Group 2014; Jorgenson et al. 2015). Numerous atlas-related tools are being developed within brain big projects. For instance, a common automated preprocessing framework has been developed within the Human Connectome Project to bring multiple magnetic resonance imaging modalities together across a large cohort of subjects (Glasser et al. 2013). The Neuroinformatics Platform within the Human Brain Project develops tools to facilitate data acquisition and annotation, assignment of the anatomical location to data, and assembly of and access to spatially indexed information (Bjerke et al. 2018). Other examples of such tools developed within the Allen Brain Atlas, BigBrain, and FSL atlas, among others, are given in (Amunts and Zilles 2015). The Scalable Brain Atlas is a collection of web services that provides unified access to a large collection of public brain atlasing resources for the human and non-human species (Bakker et al. 2015).

Therefore, despite relatively slow progress in the development of the brain atlas enabling functionality so far in comparison to that of the atlas content, the recent brain big projects will strongly drive this functionality development due to dramatic needs to handle big data including their storage, visualization, processing, analysis, and (most importantly) interpretation. Moreover, technology advancement will enhance the brain atlas functionality development to create new atlases, such as a holographic brain atlas (Petersen et al. 2019) (note that much earlier we proposed to use holography in an atlasenhanced operating room for the future (Benabid and Nowinski 2003)).

\section{Evolution of Atlas Availability}

The human brain atlases reviewed above are available to the community in various ways and this availability can be considered in terms of what is available and how it can be accessed.

The atlases are available on two major media, print and electronic, resulting in three categories: print atlases, electronic atlases on various platforms, and transitional atlases from the print to the electronic medium.

The early maps and atlases were available in a print form. The transition from the print to electronic medium has been done via two channels by (1) creating both print and electronic (bi-media) atlases, and (2) derivation of early electronic atlases from print materials by direct atlas plate digitization with no content change or with content extension by postprocessing and enhancement. Tremendous developments in computing enable almost an unlimited growth of electronic brain atlases on numerous platforms ranging from mobile solutions to leading-edge supercomputers.

Electronic brain atlas platforms can generally be classified along multiple divisions: stand-alone versus webbased; stationary versus mobile; low-cost versus highend workstations; with standard interaction and display versus VR-enhanced, augmented reality (AR)-enhanced and holographic display; standard computer versus supercomputer; and single computer versus computer clusters, networks, and cloud computing.

In neuroscience research, it is usually required to provide a brain atlas within a web-based solution. In general, brain atlases can run on various platforms. For instance, we have developed electronic brain atlases available and running on several platforms, including stand-alone plug-in library (Nowinski 2009); workstation (Nowinski 2009); notebook and desktop (for Windows and MAC) (Nowinski et al. 2005a; 2011b; Nowinski and Chua 2014); Internet-based (Nowinski et al. 2002a); mobile (iPhone (Nowinski et al. 2009c), iPad (Nowinski and Chua 2013b), Android (Nowinski et al. 2014c); and VRenabled (Serra et al. 1997). It is worth mentioning that the latter pioneering 3D brain atlas, employing a VR environment with a 3D natural interaction and stereoscopic display, was completed as early as in 1997. Brain big projects, however, such as The Human Brain Project, require leading-edge supercomputers (Amunts et al. 2016). 
From a user's standpoint, we distinguish three levels of accessibility: non-accessible, private (with limited or unlimited access), and public (with registered or unregistered access; free or payable).

The non-accessible level means that the atlas is published by its creators and available only to them, and the community is aware of the atlas but has no access to view it completely nor use it. This is probably the most common situation. Private access indicates accessibility of the atlas to a certain group of users, such as members of a consortium. Public access implies that any user may have access to the atlas after meeting certain condition(s), such as registration and/or payment. For instance, the print atlases are public, payable with unregistered access. Most educational electronic brain atlases are public and payable, such as Voxel-man (Hoehne 2001), The Human Brain in 1492 Pieces (Nowinski et al. 2011b), Focus Digital Anatomy Atlas. Neuroanatomy running on iPhone and iPad (Focus Medica), and Human Anatomy Atlas (Visible Body n.d.). Our latest and most advanced atlas The Human Brain, Head and Neck in 2953 Pieces (Nowinski et al. 2015a) is public, free of charge with registration required by its publisher at http://www. thieme.com/nowinski/.

Although restricted access may constrict in some cases atlas availability, we may guess that overall this availability substantially grows over time, as the numbers of both atlas creators and their users have been rising tremendously. This guess is corroborated by Table 1 that provides the numbers of publications over time cited on PubMed under the term "human brain atlas" indicating the growth over 470 times from 1 publication in the year 1950 to 474 publication in the year 2018. Between years 2010-2018 this growth was almost 12 fold. The overall number of citations is 4350 .

The same term "human brain atlas" searched on Google Scholar gives "about 762,000 results".

\begin{tabular}{lcccc}
\cline { 2 - 4 } $\begin{array}{l}\text { Table } 1 \text { Number of } \\
\text { citations under the term } \\
\text { "human brain atlas" on }\end{array}$ & Year & Number & Year & Number \\
\cline { 2 - 5 } PubMed versus years of & 1950 & 1 & 2011 & 174 \\
publications (as of 18 & 1960 & 1 & 2012 & 213 \\
May 2020) & 1970 & 3 & 2013 & 241 \\
& 1980 & 5 & 2014 & 297 \\
& 1985 & 18 & 2015 & 312 \\
& 1990 & 16 & 2016 & 337 \\
& 1995 & 22 & 2017 & 362 \\
& 2000 & 42 & 2018 & 474 \\
& 2005 & 121 & 2019 & 389 \\
& 2010 & 185 & 2020 & 132 \\
\hline
\end{tabular}

\section{Generations of Human Brain Atlases}

Observing the evolution of human brain maps and atlases, four atlas generations can be distinguished, namely: (1) early cortical maps, (2) print stereotactic atlases, (3) early digital atlases, and (4) advanced brain atlas platforms. From a timeframe standpoint, approximately the first atlas generation was developed in the first half of the 20th century (with the major maps published in the first three decades), the second generation in the second half of the 20th century (with the majority of atlases published in its first four decades), the third generation in the Decade of the Brain (and a handful of atlases a little earlier), and the fourth generation in the 21 st century, the century of the brain and mind.

The above review, generations of atlases, and their present state are summarized in a form of the human brain atlas evolution diagram in Fig. 1.

\section{Discussion}

The human brain atlases have been evolved tremendously, especially in recent decades, in multiple directions, as captured diagrammatically in Fig. 1. This evolution has been driven by sophisticated imaging techniques, advanced brain mapping methods, vast resources of brain data accumulated at an unprecedented rate, analytical strategies, and powerful computing. The effects of this explosive growth span from a few hand-drawn maps to multi-atlases, from print editions to web-based repositories, from $2 \mathrm{D}$ to $\mathrm{nD}$, from determinist to probabilistic, from unimodal to multi-modal, from a cortical organization to an all-level brain organization from genes to the whole brain, from normal to pathologic, from gross to nanoscales, and various combinations of these above, among others. Several papers and reports have addressed the future trends that can be expected in the human brain atlas evolution, mainly in terms of an atlas content (Toga et al. 2006; Evans et al. 2012; Amunts et al. 2014; BRAIN Working Group 2014).

The brain atlases have been employed in a wide spectrum of applications and their usefulness depends not only on the atlas content, but also on functionality and availability. Hence this review has been conducted from these four perspectives: content, applications, functionality, and availability, in contrast to other works limited mostly to atlas content.

Content-wise, the human brain atlases have evolved from a few hand-drawn maps to an atlas as a collection of maps and images; to multi-atlases; to repositories of multi-modal brain images in health and disease; to heterogeneous databases; to composable, manipulable and explorable 3D and, generally, $\mathrm{nD}$ cerebral models; to platforms for brain knowledge aggregation and integration; to brain atlas data at macro, meso, 


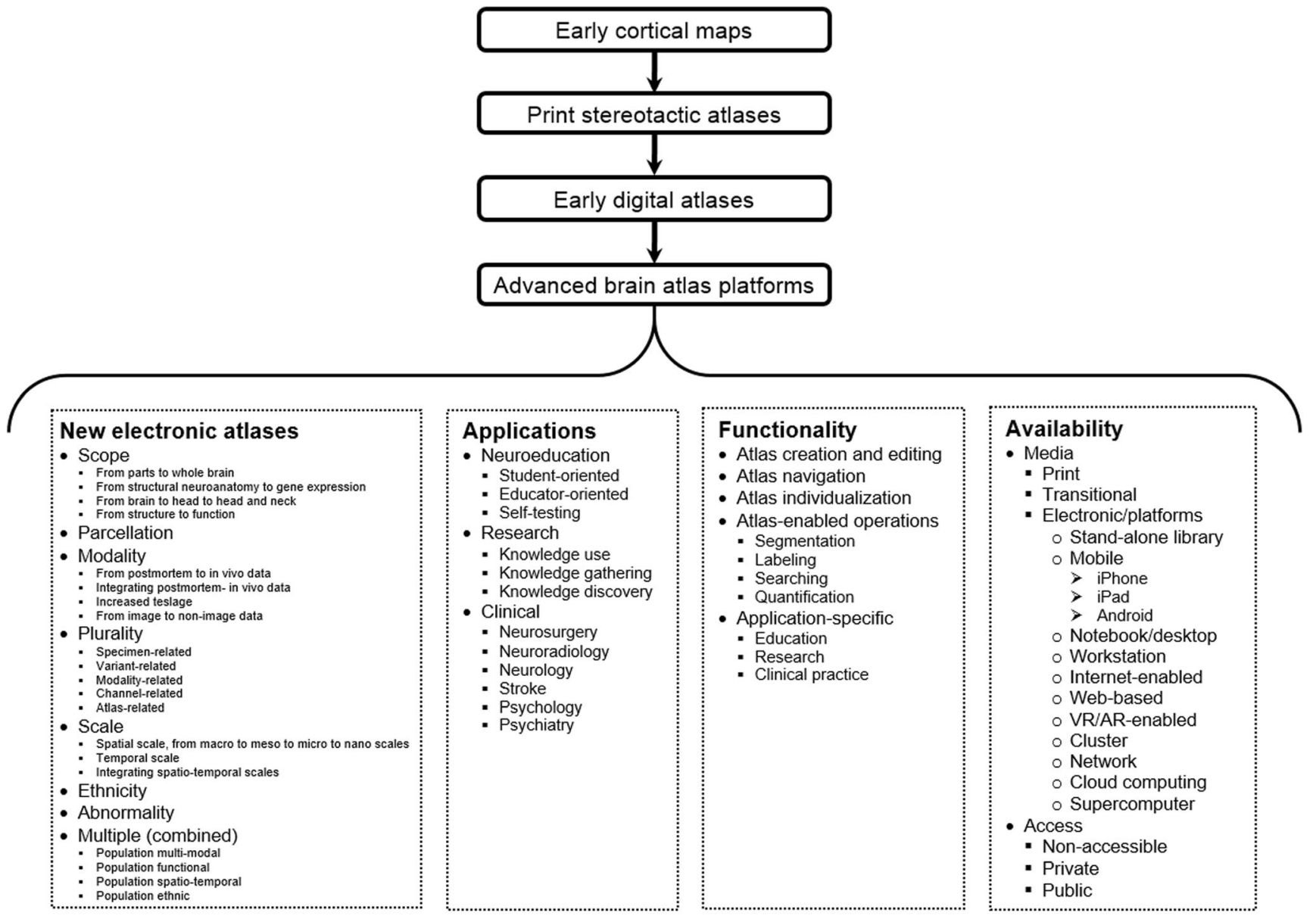

Fig. 1 A human brain atlas evolution diagram with four generations and four categories: content (only for the new electronic atlases), applications, functionality, and availability, each subsequently divided into sub-categories

micro, nano, and hybrid scales with the resolution ranging from the whole brain to synapses; and to large databases with massive amounts of data aiming to discover knowledge being developed within multi-center and/or multi-national projects and initiatives.

In an over century-long process of the human brain map and atlas creation, we have distinguished four generations: (1) early cortical maps (created in the first half of the 20th century), (2) print stereotactic atlases (published in the second half of the 20th century), (3) early digital atlases (produced predominantly in the Decade of the Brain), and (4) advanced brain atlas platforms (being developed in this century). We also noticed that every two decades mark major progress in the human brain atlas evolution. The first stereotactic brain atlases were created in the 1950th, the first digitized brain atlas was developed in the 1970th, the introduction of electronic brain atlases to clinical practice began in the 1990th followed by an explosion in brain atlas development propelled by the brain big projects that started in the 2010th .

The development of electronic brain atlases spans the last two generations and in this area we have distinguished five avenues. The recent and most prominent avenue is the creation of new electronic brain atlases. We give numerous examples of vast activities in the area of atlas content development heading in at least 23 various (though non-exhaustive) directions, which are categorized in eight groups taking into account scope (content extent), parcellation, modality, plurality, scale, ethnicity, abnormality, and a mixture of them.

Application-wise, brain atlases are employed in education, research, and clinical practice. The role and usefulness of the brain atlases have been expanding both within the research area and beyond it. The main atlas application area is research and brain knowledge gathering ranging from knowledge capturing to knowledge aggregation to knowledge discovery. Other areas of atlas applications include human brain mapping (spanning research and clinical practice), stereotactic and functional neurosurgery, neuroeducation, and specific areas, such as neuroradiology, neurology, psychology, stroke, and psychiatry.

The major application-wise shift has been from research to clinical practice, particularly in stereotactic and functional neurosurgery to treat patients. A brain atlas importance and 
potential in clinical applications have been raised and addressed by a few authors (Mori et al. 2013; BRAIN Working Group 2014). In fact, the development of brain atlas-based clinical applications for prediction, diagnosis, and treatment has been a major focus of our work. Neurosurgery planning and assessment (Nowinski 1998; 2001; 2009; Nowinski et al. 2010) was our first clinical application with anatomic, functional, and vascular atlases created. Our solutions in stereotactic and functional neurosurgery have been licensed to 13 surgical companies and integrated with surgical workstations of the leading companies, namely, Medtronic, Brainlab, and Elekta (Nowinski 2009). In addition, we have developed working prototypes in other fields for atlas-assisted brain pathology detection (Nowinski 2020), quantification of cerebral lesions (Nowinski et al. 2006), segmentation and labeling of pathological neuroimages with tumors causing a mass effect in brain cancer (Nowinski and Belov 2005), stroke management (Nowinski et al. 2006; Nowinski 2020), and stroke outcome prediction (Nowinski et al. 2014a). A vast, still unexploited, potential of brain atlas in neuroradiology has been addressed in (Nowinski 2016) describing nine applications for which working prototypes (proofs of concept) we developed earlier and presented at clinical meetings. However, despite several examples of brain atlas use in clinical applications (as products or working prototypes), these applications are still lagging behind the progress in the development of the atlas content. One of the main obstacles in introducing the brain atlas solutions to clinical practice is their validation, which is tedious, time-consuming, and costly; particularly, clinical validation is beyond a reach of a research lab because of its high cost.

In contrast to the content-wise atlas development being widely carried out by numerous groups as well as by national and multi-national consortia, the development of atlas functionality has been relatively neglected, until recently as the problem of managing data explosion requires powerful, suitable, and dedicated tools.

The early atlases evolved from bare, hand-drawn maps to print stereotactic atlases with images scalable using an overhead projector to electronic deformable atlas platforms to VRand AR-enhanced atlases to atlas-engines meaning the atlases serving as tools by themselves that support brain data management, neuroimage processing and analysis, decision making, and knowledge discovery.

From an application standpoint, the tools providing an atlas with its supporting functionality belong to three categories: (1) educational tools to explore the atlas, test knowledge, and prepare teaching materials (that can be grouped as student-oriented, educator-oriented, self-testing, and a mixture of them); (2) research tools enabling brain investigation and knowledge discovery; and (3) clinical tools to allow the clinicians to better prevent, diagnose, treat, and cure brain diseases.
Efficient and user-friendly tools are, in particular, required, in education. We have attempted to develop new education tools going beyond those available in standard educational atlases, such as Voxel-man (Hoehne 2001) or Interactive Head \& Neck (Berkovitz et al. 2003). These tools enable novel educational use of the atlas, such as self-testing and classroom assessment (Nowinski et al. 2009c) available on notebooks and mobile devices, interdisciplinary education across neuroanatomy-neuroradiology-neurology (Nowinski et Chua 2013a), advanced education for residents and clinicians with a user's "de/composable" content and context (Nowinski et al. $2014 \mathrm{~b} ; 2015 \mathrm{a}$ ), and patients' education and instruction (Nowinski 2016).

From a usage standpoint, atlas tools can be classified into two broad categories: general and specific. General tools support typical atlas-enabled operations, such as segmentation, labeling, manipulation, quantification, and querying. Specific operations are those customized to a certain field and/or particular use, such as automatic testing, generation of teaching materials, ROIs/VOIs generation and analysis, targeting, safety analysis, postoperative assessment, locusdriven analysis, decision making support, prediction of occurrence and outcomes, scan interpretation, knowledge communication, and a combination of them. From an integration standpoint, atlas-related tools can be stand-alone or directly integrated with the atlas platform.

Availability-wise, the major developmental step was obviously from print to digital atlases. Enormous progress in computing enables almost unlimited development of digital brain atlases to run on numerous platforms ranging from mobile solutions to notebooks to interactive web-based visualization platforms to VR/AR systems to high-end workstations to computer clusters, networks, and leading-edge supercomputers.

The atlas availability substantially grows over time with the numbers of both atlas creators and their users tremendously raising. If approximated by the growth of the human brain atlas publications on PubMed, the atlas availability growth from the year 1950 to the year 2018 would be over 470 times.

This work has several limitations. We have tried our best to make this state-of-the-art review in the human brain atlas evolution as complete as possible. However, the overall number of publications about this subject on PubMed is vast of 4350 (and about 762,000 references on Google Scholar) and rapidly growing, which makes a fairly complete state-of-the-art review quite difficult (if possible at all). In some areas, such as clinical applications, any relevant research publications may simply not exist, and the names of atlas creators and developers may not be disclosed by the providers to the atlas users (as, for instance, is in the case of our brain atlases licensed to surgical companies). 
The brain atlas content evolution is divided at two levels into 8 groups at the first and 23 directions at the second level. We believe that the categorization of the atlas content development into these 8 groups covers the whole landscape, though it is not unique and other criteria might be applied. This categorization is neither distinctive and some groups may overlap, for instance, the increasing scale may result in the increasing scope. The overall 23 directions in the atlas content development are not exhaustive and could be finer, especially in the last (combined) group. Likewise, the ethnicity and abnormality groups could be subdivided into directions, each for a specific ethnicity or disease, respectively.

The approximation of the atlas availability growth through the number of publications about human brain atlas may be underestimated even by a few orders. Usually a publication about a free atlas attracts a plethora of its users, and even the number of citations may not be representative. For instance, our free brain atlas (Nowinski 2017b) has a download-tocitation ratio of 160 .

This review is restricted to the human brain atlases. Several authors have overviewed non-human brain atlases for various species, including primates (marmoset, mouse lemur, squirrel monkey, macaque, and chimpanzee by Thiebaut de Schotten et al. (2018)), rodents and marsupials (rat, mouse, and opossum by Bakker et al. (2015)), and other animals by Hess et al. (2018). It is also worth mentioning that several human spinal cord atlases have been constructed, for instance, by Taso et al. (2013) and Lévy et al. (2015).

Finally, this review reflects a personal perspective and three-decade-long experience of the author in the field with 35 diverse human brain atlases created, where 15 of them have been released for the global use by Thieme Medical Publishers.

Making an overview of a field also encourages an attempt to predict future developments in brain atlasing. On one hand, the future brain research directions are well determined in the brain big projects, such as the BRAIN Initiative that sets six grand goals (BRAIN Working Group 2014). These efforts will result in the acquisition of more and more massive amounts of data and the creation of more advanced and complex brain atlases with an ever-growing scope, population, and spatial and temporal resolutions, additionally empowered by more advanced tools. On the other hand these efforts keep increasing a sort of atlas landscape inhomogeneity as well as difficulty in the atlas standardization and the integration and interpretation of various outcomes. Moreover, as the majority of efforts is devoted to brain atlas-related research, we can expect a growing imbalance and chasms among research, clinical, and educational applications of human brain atlases.

There are at least three central components related to atlas standardization, namely, an atlas coordinate system, a core reference cerebral model, and a brain atlas platform architecture.
The two most widely used coordinate systems in the neuroscience community are the Talairach system (Talairach and Tournoux 1988) and the Montreal Neurological Institute (MNI) system, and any coordinates of the latter can be converted to the Talairach space (Chau and McIntosh 2005). The Talairach coordinate system has become the standard reference for reporting the brain locations in scientific publications, though its definition is not unique. The Talairach system is based on the anterior (AC) and posterior (PC) commissure line and its center is located at the AC point landmark. However, the $\mathrm{AC}$ and $\mathrm{PC}$ point landmarks can be defined at least in four different ways resulting in a substantial discrepancy among the coordinates depending on a selected landmark definition (Nowinski 2001b). Typically the centers of the AC and PC structures are taken as the point landmarks, while the originally defined point landmarks by Talairach are beyond the AC and $\mathrm{PC}$ structures (consequently, for instance, the $\mathrm{AC}$ is missing on the coronal plane passing through the center of the coordinate system (and in my print version of his atlas, prof. Talairach "corrected" that by manually drawing it)).

A core reference high-quality cerebral model is missing in neuroinformatics. An example of such a longlasting reference model for the cerebral cortex are Brodmann's areas (Brodmann 1909). Brodmann's areas, though being one century old and based on a single brain specimen, are most widely used and remain until today applicable references in human brain mapping to correlate functional activations to the underlying neuroanatomy (Amunts and Zilles 2015), despite the creation of more advanced and accurate cortical maps (Glasser et al. 2016). For a certain period the Talairach and Tournoux (1988) atlas has played a similar role for the whole brain, despite its well-known limitations including spatial consistency as quantified by Nowinski and Thirunavuukarasuu (2009). Another example is the Schaltenbrand and Wahren (1977) atlas that for a few decades until the present remains the reference in stereotactic and functional neurosurgery.

The construction of the core virtual brain model of the highest possible quality is a complicated, tedious, and timeconsuming process, which requires sophisticated, dedicated, and precise tools and, of course, the state-of-the-art data, besides meticulous attention to details. Therefore, such a virtual brain model shall be built incrementally. We have attempted to create this kind of virtual brain model from multi-modal, multi-sequence scans of a living specimen (in a process which took almost 15 years until funding lasted), see Fig. 2. This model has been designed as modular (Nowinski 2017b) with its consecutive modules being developed and validated (including cortical areas and subcortical structures (Nowinski et al. 2012a), white matter tracts (Nowinski et al. 2012b), intracranial vasculature (Nowinski et al. 2011a), cranial nerves and nuclei (2012c), head muscle and glands (2013c), 


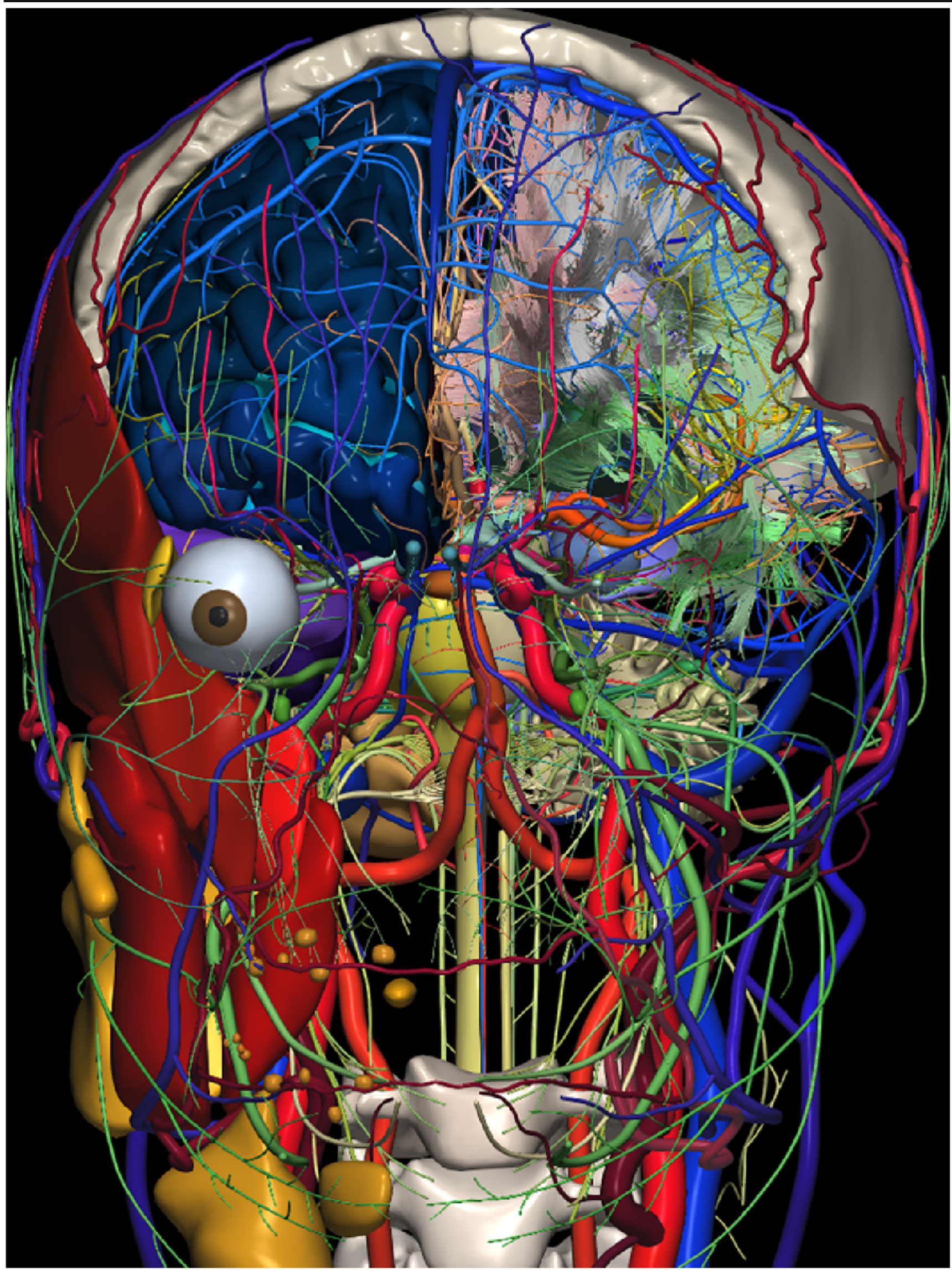


Fig. 2 The virtual decomposable brain model extended to the head and neck with about 3,000 fully segmented, labeled, and color-coded 3D components. Shown here: the right central nervous system with the cerebrum (parcellated into gyri and sulci), cerebellum, brainstem, and cervical spine; deep gray nuclei; cerebral ventricles; white matter (deep and posterior fossa); white matter tracts; right visual system; auditory system; intracranial arteries; intracranial veins; dural sinuses; cranial nerves with nuclei (partly exposed on the left side); right head (masticatory) muscles; right glands; upper skull with the frontal bone removed; cervical spine (3rd and 4th cervical vertebrae); extracranial arteries; and extracranial veins

extracranial vasculature (2015b), skull (2015c), and systems, while releasing subsequent five versions (termed The Human Brain in 1492/1969/2953 Pieces) for public use (Nowinski et al. 2011b; 2015a; Nowinski et Chua 2014). Our effort, though uncompleted, has demonstrated the feasibility of this approach.

Although the advantages of population atlases are enormous and obvious, we believe that these atlases shall be constructed around a very detailed, accurate, fully segmented, completely labeled, validated, and deterministic core model of a virtual brain created with the highest quality possible and accepted as the reference standard (similarly as Brodmann created his long-lasting standard for the cortical areas from a single specimen). Moreover, the use of a single specimen enables its continuous rescanning to create new modules with advances in imaging technology (for instance, to build our virtual brain model, the same specimen was rescanned for over 10 years on various $1.5 \mathrm{~T}, 3 \mathrm{~T}$, and $7 \mathrm{~T}$ as well as CT and US (ultrasonography) scanners). Creating a population brain atlas even with a high number of specimens but without ensuring the highest quality and thorough validation just increases the abovementioned inhomogeneity of the field with a difficulty to cross-relate various atlases.

The final factor that might potentially counterbalance this atlas inhomogeneity trend is the establishing a standardized, general architecture of the human brain atlas platform supporting equally research, clinical, and educational applications and enabling the clinicians to grow the initial core brain model with their own new data. We believe that the future human brain atlas-related research and development activities shall be founded on and benefitted from such a standard framework containing the core virtual brain model cum the brain atlas platform general architecture.

\section{Summary}

We have attempted here to track enormous transformational advances in the human brain atlas evolution from hand-drawn cortical maps to print brain atlases to digital atlases with tools to multi-modal and population atlases in health and disease to mega multi-atlases across the lifespan to atlas platforms at macro, meso, micro, and nanoscales, as diagrammatically summarized in Fig. 1. This atlas evolution review differentiates from other works, usually focusing on the atlas content mostly in research applications, as we take here a wider perspective and analyze this evolution in four categories: content, applications, functionality, and availability. Four generations of human brain atlases are distinguished, namely, early cortical maps, print stereotactic atlases, early digital atlases, and advanced brain atlas platforms. The development of electronic brain atlases spans the last two generations and in this area we identify five avenues, the recent and most prominent is the creation of new electronic brain atlases. The brain atlas content evolution in this avenue is categorized in eight groups taking into account scope, parcellation, modality, plurality, scale, ethnicity, abnormality, and a mixture of them, in which, in turn, the atlas developments are heading in 23 various directions.

We suggest that the future human brain atlas-related research and development activities shall be founded on and benefitted from a standard framework containing the core virtual brain model cum the brain atlas platform general architecture.

Acknowledgements The author's work on brain atlas development was funded by ASTAR, Singapore.

\section{Compliance with Ethical Standards}

\section{Conflict of Interest None.}

Open Access This article is licensed under a Creative Commons Attribution 4.0 International License, which permits use, sharing, adaptation, distribution and reproduction in any medium or format, as long as you give appropriate credit to the original author(s) and the source, provide a link to the Creative Commons licence, and indicate if changes were made. The images or other third party material in this article are included in the article's Creative Commons licence, unless indicated otherwise in a credit line to the material. If material is not included in the article's Creative Commons licence and your intended use is not permitted by statutory regulation or exceeds the permitted use, you will need to obtain permission directly from the copyright holder. To view a copy of this licence, visit http://creativecommons.org/licenses/by/4.0/.

\section{References}

A.D.A.M. (1996). A.D.A.M Animated Dissection of Anatomy for Medicine. User's Guide, A.D.A.M.

Afshar, E., Watkins, E. S., \& Yap, J. C. (1978). Stereotactic Atlas of the Human Brainstem and Cerebellar Nuclei. New York: Raven Press.

Alho, E. J. L., Grinberg, L., \& Heinsen, H. (2011). Review of printed and electronic stereotactic atlases of the human brain. In J. F. P. Peres (Ed.), Neuroimaging for Clinicians: Combining Research and Practice (pp. 145-172). Rijeka: InTech. 
Alivisatos, A. P., Chun, M., Church, G. M., Greenspan, R. J., Roukes, M. L., \& Yuste, R. (2012). The brain activity map project and the challenge of functional connectomics. Neuron, 74(6), 970-4.

Alivisatos, A. P., Andrews, A. M., Boyden, E. S., Chun, M., Church, G. M., Deisseroth, K., Donoghue, J. P., Fraser, S. E., LippincottSchwartz, J., Looger, L. L., Masmanidis, S., McEuen, P. L., Nurmikko, A. V., Park, H., Peterka, D. S., Reid, C., Roukes, M. L., Scherer, A., Schnitzer, M., Sejnowski, T. J., Shepard, K. L., Tsao, D., Turrigiano, G., Weiss, P. S., Xu, C., Yuste, R., \& Zhuang, X. (2013). Nanotools for neuroscience and brain activity mapping. ACS Nano, 7(3), 1850-1866.

Aljabar, P., Heckemann, R. A., Hammers, A., Hajnal, J. V., \& Rueckert, D. (2009). Multi-atlas based segmentation of brain images: atlas selection and its effect on accuracy. Neuroimage, 46, 726-738.

Amunts, K., \& Zilles, K. (2015). Architectonic mapping of the human brain beyond Brodmann. Neuron, 88(6), 1086-1107.

Amunts, K., Lenzen, M., Friederici, A. D., Schleicher, A., Morosan, P., Palomero-Gallagher, N., \& Zilles, K. (2010). Broca's region: novel organizational principles and multiple receptor mapping. PLoS Biology, 8, e1000489.

Amunts, K., Lepage, C., Borgeat, L., Mohlberg, H., Dickscheid, T., Rousseau, M. É., ... Evans, A. C. (2013). Bigbrain: An ultrahighresolution 3D human brain model. Science, 340(6139), 1472-1475.

Amunts, K., Hawrylycz, M. J., Van Essen, D. C., Van Horn, J. D., Harel, N., Poline, J. B., De Martino, F., Bjaalie, J. G., Dehaene-Lambertz, G., Dehaene, S., Valdes-Sosa, P., Thirion, B., Zilles, K., Hill, S. L., Abrams, M. B., Tass, P. A., Vanduffel, Evans, A. C., \& Eickhoff, S. B. (2014). Interoperable atlases of the human brain. Neuroimage, 99, 525-32. https://doi.org/10.1016/j.neuroimage.2014.06.010.

Amunts, K., Ebell, C., Muller, J., Telefont, M., Knoll, A., \& Lippert, T. (2016). The Human Brain Project: creating a European research infrastructure to decode the human brain. Neuron, 92(3), 574-581.

Andrew, J., \& Watkins, E. S. (1969). A Stereotaxic Atlas of the Human Thalamus and Adjacent Structures. A Variability Study. Baltimore: Williams and Wilkins.

Arsiwalla XD, Zucca R, Betella A, et al. (2015). Network dynamics with BrainX(3): a large-scale simulation of the human brain network with realtime interaction. Frontiers in Neuroinformatics, 9:02 https://doi. org/10.3389/fninf.2015.00002.eCollection2015.

Artaechevarria, X., Munoz-Barrutia, A., \& Ortiz-de Solorzano, C. (2009). Combination strategies in multi-atlas image segmentation: application to brain MR data. IEEE Transactions on Medical Imaging, 28(8), 1266-1277.

Ashburner, J. (2009). Computational anatomy with the SPM software. Magnetic Resonance Imaging, 27(8), 1163-1174.

Assaf, Y., Alexander, D. C., Jones, D. K., et al. (2013). The CONNECT project: Combining macro- and micro-structure. Neuroimage, 80 , 273-282.

Bajcsy, R., Lieberson, R., \& Reivich, M. (1983). A computerized system for the elastic matching of deformed radiographic images to idealized atlas images. Journal of Computer Assisted Tomography, 7, 618-625.

Baker, C. M., Burks, J. D., Briggs, R. G., et al. (2018). A connectomic atlas of the human cerebrum Chap. 1: introduction, methods, and significance. Operative Neurosurgery, 15(6S), S1-S9.

Bakker, R., Tiesinga, P., \& Kötter, R. (2015). The Scalable Brain Atlas: instant web-based access to public brain atlases and related content. Neuroinformatics, 13, 353-366.

Bassett, D. L. (1952). A stereoscopic atlas of human anatomy. Portland: Sawyer's.

Bayer. (1996). Microvascular Atlas of the Head and Neck. CD-ROM for Macintosh and Windows.

Beliveau, V., Ganz, M., Feng, L., Ozenne, B., Højgaard, L., Fisher, P. M., Svarer, C., Greve, D. N., \& Knudsen, G. M. (>2017). A highresolution in vivo atlas of the human brain's serotonin system. The Journal of Neuroscience, 37(1), 120-128.
Benabid, A. L., \& Nowinski, W. L. (2003). Intraoperative robotics for the practice of neurosurgery: a surgeon's perspective. In: The Operating Room for the 21th Century (ed. Apuzzo ML), American Association of Neurological Surgeons, Rolling Meadows, Illinois, 2003:103-118.

Berkovitz, B., Kirsch, C., Moxham, B., Alusi, G., \& Cheeseman, T. (2003). Interactive Head \& Neck. CD-ROM PC and Mac compatible. London: Primal.

Bernier, M., Cunnane, S. C., \& Whittingstall, K. (2018). The morphology of the human cerebrovascular system. Human Brain Mapping, 39(12), 4962-4975.

Bertrand, G., Olivier, A., \& Thompson, C. J. (1974). Computer display of stereotaxic brain maps and probe tracts. Acta Neurochirurgica Supplement, 21, 235-243.

Bhalerao, G. V., Parlikar, R., Agrawal, R., Shivakumar, V., Kalmady, S. V., Rao, N. P., Agarwal, S. M., Narayanaswamy, J. C., Reddy, Y. C. J., \& Venkatasubramanian, G. (2018). Construction of populationspecific Indian MRI brain template: Morphometric comparison with Chinese and Caucasian templates. Asian Journal of Psychiatry, 35, 93-100.

Bjerke, I. E., Øvsthus, M., Papp, E. A., Yates, S. C., Silvestri, L., Fiorilli, J., Pennartz, C. M. A., Pavone, F. S., Puchades, M. A., Leergaard, T. B., \& Bjaalie, J. G. (2018). Data integration through brain atlasing: Human Brain Project tools and strategies. European Psychiatry, 50, $70-76$.

Bohm, C., Greitz, T., Kingsley, D., Berggren, B. M., \& Olsson, L. (1983). Adjustable computerized stereotaxic brain atlas for transmission and emission tomography. American Journal of Neuroradiology, 4(3), $731-733$

Bozek, J., Makropoulos, A., Schuh, A., Fitzgibbon, S., Wright, R., Glasser, M. F., Coalson, T. S., O’Muircheartaigh, J., Hutter, J., Price, A. N., Cordero-Grande, L., Teixeira, R. P. A. G., Hughes, E., Tusor, N., Baruteau, K. P., Rutherford, M. A., Edwards, A. D., Hajnal, J. V., Smith, S. M., Rueckert, D., Jenkinson, M., \& Robinson, E. C. (2018). Construction of a neonatal cortical surface atlas using Multimodal Surface Matching in the Developing Human Connectome Project. Neuroimage, 179, 11-29.

BRAIN Working Group. (2014). BRAIN 2025. A Scientific Vision. NIH; https://www.braininitiative.nih.gov/pdf/BRAIN2025_508C.pdf.

Breshears, J. D., Molinaro, A. M., \& Chang, E. F. (2015). A probabilistic map of the human ventral sensorimotor cortex using electrical stimulation.. Journal of Neurosurgery, 123(2), 340-349.

Briggs, R. G., Conner, A. K., Baker, C. M., Burks, J. D., Glenn, C. A., Sali, G., Battiste, J. D., O’Donoghue, D. L., \& Sughrue, M. E. (2018). A connectomic atlas of the human cerebrum-Chap. 18: The Connectional Anatomy of Human Brain Networks. Operative Neurosurgery, 15(suppl_1), S470-S480.

Brodmann, K. (1909). Vergleichende Lokalisationslehre der Grosshirnrinde in ihren Prinzipien dargestellt auf Grund des Zellenbaues. Leipzig: Barth JA.

Campbell, A. W. (1905). Histological Studies on the Localisation of Cerebral Function. Cambridge: Cambridge University Press.

Chakravarty, M. M., Bertrand, G., Hodge, C. P., et al. (2006). The creation of a brain atlas for image guided neurosurgery using serial histological data. Neuroimage, 30, 359-376.

Chau, W., McIntosh, A. R. (2005). The Talairach coordinate of a point in the MNI space: how to interpret it. Neuroimage, 25(2):408-416.

Chen, Z., Qiu, T., Huo, L., Yu, L., Shi, H., Zhang, Y., \& Wang, H. (2018). Deformable head atlas of Chinese adults incorporating inter-subject anatomical variations. IEEE access : practical innovations, open solutions, 6. https://doi.org/10.1109/ACCESS.2018. 2869331.

Chenot, Q., Tzourio-Mazoyer, N., Rheault, F., Descoteaux, M., Crivello, F., Zago, L., Mellet, E., Jobard, G., Joliot, M., Mazoyer, B., \& Petit, L. (2019). A population-based atlas of the human pyramidal tract in 
410 healthy participants. Brain Structure and Function, 224(2), 599-612.

Cho, Z. H., Kim, Y. B., Han, J. Y., Min, H. K., Kim, K. N., Choi, S. H., Veklerov, E., \& Shepp, L. A. (2008). New brain atlas - mapping the human brain in vivo with 7.0 T MRI and comparison with postmortem histology: will these images change modern medicine? International Journal of Imaging Systems and Technology, 18(1), $2-8$.

Chung, M. S., \& Park, J. S. (2007). Applications of the Visible Korean Human. In V. G. Duffy (Ed.), Digital Human Modeling. ICDHM 2007 (Vol. 4561, pp. 353-362). Berlin: Springer. Lecture Notes in Computer Science.

Craddock, R. C., James, G. A., Holtzheimer, P. E. 3rd, Hu, X. P., \& Mayberg, H. S. (2012). A whole brain fMRI atlas generated via spatially constrained spectral clustering. Human Brain Mapping, 33, 1914-1928.

Dergachyova, O., Zhao, Y., Haegelen, C., Jannin, P., \& Essert, C. (2018). Automatic preoperative planning of DBS electrode placement using anatomo-clinical atlases and volume of tissue activated. International Journal of Computer Assisted Radiology and Surgery, 13(7), 1117-1128.

de Haan, B., \& Karnath, H. O. (2017). 'Whose atlas I use, his song I sing?' - The impact of anatomical atlases on fiber tract contributions to cognitive deficits after stroke. Neuroimage, 163, 301-309.

Dev, P., Coppa, G. P., \& Tancred, E. (1992). BrainStorm: desiging in interactive neuroanatomy atlas. Radiology, 185(P), 413.

Dickie, D. A., Shenkin, S. D., Anblagan, D., et al. (2017). Whole brain magnetic resonance image atlases: a systematic review of existing atlases and caveats for use in population imaging. Frontiers in Neuroinformatics, 11, 1. https://doi.org/10.3389/fninf.2017.00001. eCollection 2017.

Diedrichsen, J., Balsters, J. H., Flavell, J., et al. (2009). A probabilistic MR atlas of the human cerebellum. NeuroImage, 46(1), 39-46; https://doi.org/10.1016/j.neuroimage.2009.01.045.

Dimitrova, A., Zeljko, D., Schwarze, F., et al. (2006). Probabilistic 3D MRI atlas of the human cerebellar dentate/interposed nuclei. NeuroImage, 30(1), 12-25.

Ding, S. L., Royall, J. J., Sunkin, S. M., Ng, L., Facer, B. A., Lesnar, P., Guillozet-Bongaarts, A., McMurray, B., Szafer, A., Dolbeare, T. A., Stevens, A., Tirrell, L., Benner, T., Caldejon, S., Dalley, R. A., Dee, N., Lau, C., Nyhus, J., Reding, M., Riley, Z. L., Sandman, D., Shen, E., van der Kouwe, A., Varjabedian, A., Wright, M., Zöllei, L., Dang, C., Knowles, J. A., Koch, C., Phillips, J. W., Sestan, N., Wohnoutka, P., Zielke, H. R., Hohmann, J. G., Jones, A. R., Bernard, A., Hawrylycz, M. J., Hof, P. R., Fischl, B., \& Lein, E. S. (2016). Comprehensive cellular-resolution atlas of the adult human brain. The Journal of Comparative Neurology, 524(16), 31273481.

Drury, H. A., Van Essen, D. C. (1997). Functional specializations in human cerebral cortex analyzed using the visible man surface-based atlas. Human Brain Mapping, 5(4):233-237.

Dunås, T., Wåhlin, A., Ambarki, K., Zarrinkoob, L., Birgander, R., Malm, J., \& Eklund, A. (2016). Automatic labeling of cerebral arteries in magnetic resonance angiography. MAGMA, 29(1), 39-47. https://doi.org/10.1007/s10334-015-0512-5.

Dunås, T., Wåhlin, A., Ambarki, K., et al. (2017). A stereotactic probabilistic atlas for the major cerebral arteries. Neuroinformatics, 15(1), 101-110. https://doi.org/10.1007/s12021-016-9320-y.

Duvernoy, H. M. (1988). The Human Hippocampus: Atlas of Applied Anatomy. Munich: Bergman.

Duvernoy, H. M. (1995). The Human Brain Stem and Cerebellum. Surface, Structure, Vascularization, and Three-Dimensional Sectional Anatomy, with MRI. Wien: Springer.

Ecker, J. R., Geschwind, D. H., Kriegstein, A. R., Ngai, J., Osten, P., Polioudakis, D., Regev, A., Sestan, N., Wickersham, I. R., \& Zeng, H. (2017). The BRAIN Initiative Cell Census Consortium: Lessons learned toward generating a Comprehensive Brain Cell Atlas. Neuron, 96(3), 542-557.

Eickhoff, S. B., Stephan, K. E., Mohlberg, H., Grefkes, C., Fink, G. R., Amunts, K., \& Zilles, K. (2005). A new SPM toolbox for combining probabilistic cytoarchitectonic maps and functional imaging data. Neuroimage, 25, 1325-1335.

Evans, A. C., Janke, A. L., Collins, D. L., \& Baillet, S. (2012). Brain templates and atlases. Neuroimage, 62(2), 911-922.

Faillenot, I., Heckemann, R. A., Frot, M., \& Hammers, A. (2017). Macroanatomy and 3D probabilistic atlas of the human insula. NeuroImage, 150, 88-98.

Fan, L., Li, H., Zhuo, J., Zhang, Y., Wang, J., Chen, L., Yang, Z., Chu, C., Xie, S., Laird, A. R., Fox, P. T., Eickhoff, S. B., Yu, C., \& Jiang, T. (2016). The human brainnetome atlas: a new brain atlas based on connectional architecture. Cerebral Cortex, 26, 3508-3526.

Felten, D. L., O'Banion, M. K., Maida, M. E. (2015). Netter's Atlas of Neuroscience ( $3^{\text {rd }}$ edition). Elsevier, Amsterdam.

Figley, T. D., Mortazavi Moghadam, B., Bhullar, N., Kornelsen, J., Courtney, S. M., \& Figley, C. R. (2017). Probabilistic white matter atlases of human auditory, basal ganglia, language, precuneus, sensorimotor, visual and visuospatial networks. Frontiers in Human Neuroscience, 11, 306. https://doi.org/10.3389/fnhum.2017.00306. eCollection 2017.

Finnis, K., Starreveld, Y., Parrent, A., Sadikot, A., \& Peters, T. (2003). Three-dimensional database of subcortical electrophysiology for image-guided stereotactic functional neurosurgery. IEEE Transactions on Medical Imaging, 22(1), 93-104.

Fischl, B. (2012). FreeSurfer. NeuroImage, 62(2). 774-781. http:// freesurfer.net/.

Flechsig, P. (1920). Anatomie des menschlichen Gehirns und Rückenmarks auf myelogenetischer Grundlage. Leipzig: Thieme.

Focus Medica. Focus Digital Anatomy Atlas. Neuroanatomy. Available at https://apps.apple.com/us/app/neuroanatomy-digital-anatomy/ id923683661

Fonov, V., Evans, A. C., Botteron, K., et al. (2011). Unbiased average age-appropriate atlases for pediatric studies. Neuroimage, 54, 313 327.

Frackowiak, R., \& Markram, H. (2015). The future of human cerebral cartography: a novel approach. Philosophical Transactions of the Royal Society of London. Series B, Biological Sciences, 370. https:// doi.org/10.1098/rstb.2014.0171.

Ganser, K. A., Dickhaus, H., Metzner, R., \& Wirtz, C. R. (2004). A deformable digital brain atlas system according to Talairach and Tournoux. Medical Image Analysis, 8(1), 3-22.

Gee, J. C., Reivich, M., \& Bajcsy, R. (1993). Elastically deforming 3D atlas to match anatomical brain images. Journal of Computer Assisted Tomography, 17, 225-236.

Geyer, S., Weiss, M., Reimann, K., Lohmann, G., \& Turner, R. (2011). Microstructural parcellation of the human cerebral cortex - from Brodmann's postmortem map to in vivo mapping with high-field magnetic resonance imaging. Frontiers in Human Neuroscience, 5, 19.

Glasser, M. F., Sotiropoulos, S. N., Wilson, J. A., et al. (2013). The minimal preprocessing pipelines for the Human Connectome Project. NeuroImage, 80, 105-24.

Glasser, M. F., Coalson, T. S., Robinson, E. C., Hacker, C. D., Harwell, J., Yacoub, E., Ugurbil, K., Andersson, J., Beckmann, C. F., Jenkinson, M., Smith, S. M., \& van Essen, D. C. (2016). A multimodal parcellation of human cerebral cortex. Nature, 536, 171-178.

Gorgolewski, K. J., Varoquaux, G., Rivera, G., et al. (2016). NeuroVault.org: A repository for sharing unthresholded statistical maps, parcellations, and atlases of the human brain. Neuroimage, $124,1242-1244$.

Greitz, T., Bohm, C., Holte, S., \& Eriksson, L. (1991). A computerized brain atlas: construction, anatomical content, and some applications. Journal of Computer Assisted Tomography, 15(1), 26-38. 
Hammers, A., Chen, C. H., Lemieux, L., Allom, R., Vossos, S., Free, S. L., et al. (2007). Statistical neuroanatomy of the human inferior frontal gyrus and probabilistic atlas in a standard stereotaxic space. Human Brain Mapping, 28, 34-38. https://doi.org/10.1002/hbm. 20254.

Hawrylycz, M. J., Lein, E. S., Guillozet-Bongaarts, A. L., Shen, E. H., Ng, L., Miller, J. A., van de Lagemaat, L. N., Smith, K. A., Ebbert, A., Riley, Z. L., Abajian, C., Beckmann, C. F., Bernard, A., Bertagnolli, D., Boe, A. F., Cartagena, P. M., Chakravarty, M. M., Chapin, M., Chong, J., Dalley, R. A., David Daly, B., Dang, C., Datta, S., Dee, N., Dolbeare, T. A., Faber, V., Feng, D., Fowler, D. R., Goldy, J., Gregor, B. W., Haradon, Z., Haynor, D. R., Hohmann, J. G., Horvath, S., Howard, R. E., Jeromin, A., Jochim, J. M., Kinnunen, M., Lau, C., Lazarz, E. T., Lee, C., Lemon, T. A., Li, L., Li, Y., Morris, J. A., Overly, C. C., Parker, P. D., Parry, S. E., Reding, M., Royall, J. J., Schulkin, J., Sequeira, P. A., Slaughterbeck, C. R., Smith, S. C., Sodt, A. J., Sunkin, S. M., Swanson, B. E., Vawter, M. P., Williams, D., Wohnoutka, P., Zielke, H. R., Geschwind, D. H., Hof, P. R., Smith, S. M., Koch, C., Grant, S. G. N., \& Jones, A. R. (2012). An anatomically comprehensive atlas of the adult human brain transcriptome. Nature, 489(7416), 391-399.

Haegelen, C., Baumgarten, C., Houvenaghel, J. F., Zhao, Y., Péron, J., Drapier, S., Jannin, P., \& Morandi, X. (2018). Functional atlases for analysis of motor and neuropsychological outcomes after medial globus pallidus and subthalamic stimulation. PLoS One, 13(7), e0200262. https://doi.org/10.1371/journal.pone.0200262.

Hess, A., Hinz, R., Keliris, G. A., et al. (2018). On the usage of brain atlases in neuroimaging research. Molecular Imaging and Biology, 20(5), 742-749. https://doi.org/10.1007/s11307-018-1259-y.

Hoehne, K. H., Bomans, M., Riemer, M., Schubert, R., Tiede, U., \& Lierse, W. (1992). A volume-based anatomical atlas. IEEE Comput Graphics Applications, 12, 72-78.

Hoehne, K. H. (2001). VOXEL-MAN, Part 1: Brain and Skull, Version 2.0. Heidelberg: Springer.

Huck, J., Wanner, Y., Fan, A. P., Jäger, A. T., Grahl, S., Schneider, U., Villringer, A., Steele, C. J., Tardif, C. L., Bazin, P. L., \& Gauthier, C. J. (2019). High resolution atlas of the venous brain vasculature from 7 T quantitative susceptibility maps. Brain Structure and Function, 224, 2467-2485.

Iglesias, J. E., Insausti, R., Lerma-Usabiaga, G., Bocchetta, M., Van Leemput, K., Greve, D. N., van der Kouwe, A.; Alzheimer's Disease Neuroimaging Initiative, Fischl, B., Caballero-Gaudes, C., \& Paz-Alonso, P. M. (2018). A probabilistic atlas of the human thalamic nuclei combining ex vivo MRI and histology. Neuroimage, 183, 314-326.

James, G. A., Hazaroglu, O., \& Bush, K. A. (2016). A human brain atlas derived via $n$-cut parcellation of resting-state and task-based fMRI data. Magnetic Resonance Imaging, 34(2), 209-218.

Jiang, T. (2013). Brainnetome: a new -ome to understand the brain and its disorders. Neuroimage, 80, 263-272.

Jenkinson, M., Beckmann, C. F., Behrens, T. E., Woolrich, M. W., \& Smith, S. M. (2012). FSL. Neuroimage, 62(2), $782-90$.

Jennings, J. E., Kassam, A. B., Fukui, M. B., Monroy-Sosa, A., Chakravarthi, S., Kojis, N., \& Rovin, R. A. (2018). The Surgical White Matter Chassis: A practical 3-dimensional atlas for planning subcortical surgical trajectories. Operative Neurosurgery, 14(5), 469-482.

Johnson, K. A., \& Becker, J. A. (1999). The Whole Brain Atlas. http:// www.med.harvard.edu/aanlib.

Jorgenson, L. A., Newsome, W. T., Anderson, D. J., Bargmann, C. I., Brown, E. N., Deisseroth, K., Donoghue, J. P., Hudson, K. L., Ling, G. S., MacLeish, P. R., Marder, E., Normann, R. A., Sanes, J. R., Schnitzer, M. J., Sejnowski, T. J., Tank, D. W., Tsien, R. Y., Ugurbil, K., \& Wingfield, J. C. (2015). The BRAIN Initiative: developing technology to catalyse neuroscience discovery.
Philosophical Transactions of the Royal Society London B: Biological Sciences, 370(1668).

Juanes, J. A., Ruisoto, P., Riesco, J. M., \& Prats, A. (2012). Development of anatomical and radiological digital brain maps. European Journal of Anatomy, 16(2), 91-97.

Kall, B. A., Kelly, P. J., Goerss, S., \& Frieder, G. (1985). Methodology and clinical experience with Computed Tomography and a computer-resident stereotactic atlas. Neurosurgery, 17(3), 400-407.

Kanton, S., Boyle, M. J., He, Z., Santel, M., Weigert, A., Sanchís-Calleja, F., Guijarro, P., Sidow, L., Fleck, J. S., Han, D., Qian, Z., Heide, M., Huttner, W. B., Khaitovich, P., Pääbo, S., Treutlein, B., \& Camp, J. G. (2019). Organoid single-cell genomic atlas uncovers humanspecific features of brain development. Nature, 574(7778), 418 422.

Kazarnovskaya, M. I., Borodkin, S. M., \& Shabalov, V. A. (1991). 3-D computer model of subcortical structures of human brain. Computers in Biology and Medicine, 21, 451-457.

Kikinis, R., Shenton, M. E., Iosifescu, D. V., et al. (1996). A digital brain atlas for surgical planning, model-driven segmentation, and teaching. IEEE Trans on Visualization and Comp Graphics, 2(3), 232241.

Klein, A., Andersson, J., Ardekani, B. A., et al. (2009). Evaluation of 14 nonlinear deformation algorithms applied to human brain MRI registration. NeuroImage, 46(3), 786-802.

Kling-Petersen, T., \& Rydmark, M. (1997). The BRAIN project: an interactive learning tool using desktop virtual reality on personal computers. Studies in Health Technology and Informatics, 39, 529-538.

Kraus, G. E., \& Bailey, G. J. (1994). Microsurgical Anatomy of the Brain. A Stereo Atlas. Baltimore: Williams and Wilkins.

Krauth, A., Blanc, R., Poveda, A., Jeanmonod, D., Morel, A., \& Székely, G. (2010). A mean three-dimensional atlas of the human thalamus: generation from multiple histological data. Neuroimage, 49(3), 2053-62.

Kuklisova-Murgasova, M., Aljabar, P., Srinivasan, L., Counsell, S. J., Doria, V., Serag, A., Gousias, I. S., Boardman, J. P., Rutherford, M. A., Edwards, A. D., Hajnal, J. V., \& Rueckert, D. (2011). A dynamic 4D probabilistic atlas of the developing brain. Neuroimage, 54(4), 2750-63.

Labra, N., Guevara, P., Duclap, D., Houenou, J., Poupon, C., Mangin, J. F., \& Figueroa, M. (2017). Fast automatic segmentation of white matter streamlines based on a multi-subject bundle atlas. Neuroinformatics, 15(1), 71-86.

Lalys, F., Haegelen, C., Ferre, J. C., El-Ganaoui, O., \& Jannin, P. (2010). Construction and assessment of a 3-T MRI brain template. Neuroimage, 49, 345-354.

Lancaster, J. L., Woldorff, M. G., Parsons, L. M., Liotti, M., Freitas, C. S., Rainey, L., Kochunov, P. V., Nickerson, D., Mikiten, S. A., Fox, P. T. (2000). Automated Talairach atlas labels for functional brain mapping. Human Brain Mapping; 10(3):120-131.

Lee, J. S., Lee, D. S., Kim, J., Kim, Y. K., Kang, E., Kang, H., Kang, K. W., Lee, J. M., Kim, J. J., Park, H. J., Kwon, J. S., Kim, S. I., Yoo, T. W., Chang, K. H., \& Lee, M. C. (2005). Development of Korean standard brain templates. Journal of Korean Medical Science, 20, 483-488.

Lehmann, E. D., Hawkes, D. J., Hill, D. L., Bird, C. F., Robinson, G. P., Colchester, A. C., \& Maisey, M. N. (1991). Computer-aided interpretation of SPECT images of the brain using an MRI-derived 3D neuro-anatomical atlas. Medical Informatics, 16, 151-166.

Lehman, V. T., Black, D. F., DeLone, D. R., Blezek, D. J., Kaufmann, T. J., Brinjikji, W., \& Welker, K. M. (2020). Current concepts of crosssectional and functional anatomy of the cerebellum: a pictorial review and atlas. The British Journal of Radiology, 8, 20190467. https://doi.org/10.1259/bjr.20190467.

Lemaire, J. J., De Salles, A., Coll, G., El Ouadih, Y., Chaix, R., Coste, J., Durif, F., Makris, N., \& Kikinis, R. (2019). MRI atlas of the human 
deep brain. Frontiers in Neurology, 10, 851. https://doi.org/10.3389/ fneur.2019.00851. eCollection 2019.

Lévy, S., Benhamou, M., Naaman, C., Rainville, P., Callot, V., \& CohenAdad, J. (2015). White matter atlas of the human spinal cord with estimation of partial volume effect. NeuroImage, 119, 262-271.

Li, Q., Ran, X., Zhang, S. X., Tan, L., \& Qiu, M. (2014). A digital interactive human brain atlas based on Chinese visible human datasets for anatomy teaching. Journal of Craniofacial Surgery, 25(1), 303-307.

Li, X., Chen, L., Kutten, K., Ceritoglu, C., Li, Y., Kang, N., Hsu, J. T., Qiao, Y., Wei, H., Liu, C., Miller, M. I., Mori, S., Yousem, D. M., van Zijl, P. C. M., \& Faria, A. V. (2019). Multi-atlas tool for automated segmentation of brain gray matter nuclei and quantification of their magnetic susceptibility. Neuroimage;191:337-349.

Liang, P., Shi, L., Chen, N., et al. (2015). Construction of brain atlases based on a multi-center MRI dataset of 2020 Chinese adults. Scientific Reports, 5, 18216. https://doi.org/10.1038/srep18216.

Liu, Y., D'Haese, P. F., Newton, A. T., \& Dawant, B. M. (2020). Generation of human thalamus atlases from $7 \mathrm{~T}$ data and application to intrathalamic nuclei segmentation in clinical $3 \mathrm{~T}$ T1-weighted images. Magnetic Resonance Imaging, 65, 114-128. https://doi. org/10.1016/j.mri.2019.09.004.

Lötjönen, J. M., Wolz, R., Koikkalainen, J. R., et al. (2010). Fast and robust multi-atlas segmentation of brain magnetic resonance images. NeuroImage, 49(3), 2352-2365.

Mai, J., Paxinos, G.. Assheuer, J. (2004). ). Atlas of the Human Brain (3th ed.). New York: Academic.

Mandal, P. K., Mahajan, R., \& Dinov, I. D. (2012). Structural brain atlases: design, rationale, and applications in normal and pathological cohorts. Journal of Alzheimer's Disease, 31(Suppl 3), S169S188.

Marchenko, Y., Volkau, I., \& Nowinski, W. L. (2010). Vascular Editor: from images to 3D vascular models. Journal of Digital Imaging, 23(4), 386-398.

Markram, H., Muller, E., Ramaswamy, S., et al. (2015). Reconstruction and simulation of neocortical microcircuitry. Cell, 163(2), 456-492.

Maye, A., Wenckebach, T. H., \& Hege, H. C. (2006). Visualization, reconstruction, and integration of neuronal structures in digital brain atlases. International Journal of Neuroscience, 116(4), 431-459.

Mazziotta, J. C., Toga, A. W., Evans, A., Fox, P., \& Lancaster, J. (1995). A probabilistic atlas of the human brain: Theory and rationale for its development. Neuroimage, 2, 89-101.

Mazziotta, J., Toga, A., Evans, A., Fox, P., Lancaster, J., et al. (2001). A probabilistic atlas and reference system for the human brain: International Consortium for Brain Mapping (ICBM). Philosophical Transactions of the Royal Society London B: Biological Sciences, 356(1412), 1293-1322.

McKetney, J., Runde, R. M., Hebert, A. S., Salamat, S., Roy, S., \& Coon, J. J. (2019). Proteomic atlas of the human brain in Alzheimer's Disease. Journal of Proteome Research, 18(3), 1380-1391.

Mega, M. S., Dinov, I. D., Mazziotta, J. C., Manese, M., Thompson, P. M., Lindshield, C., Moussai, J., Tran, N., Olsen, K., Zoumalan, C. I., Woods, R. P., \& Toga, A. W. (2005). Automated brain tissue assessment in the elderly and demented population: Construction and validation of a sub-volume probabilistic brain atlas. NeuroImage, 26, 1009-1018.

Meola, A., Yeh, F. C., Fellows-Mayle, W., et al. (2016). Human connectome-based tractographic atlas of the brainstem connections and surgical approaches. Neurosurgery, 79(3), $437-55$.

Minoshima, S., Koeppe, R. A., Frey, K. A., Ishihara, M., \& Kuhl, D. E. (1994). Stereotactic PET atlas of the human brain: aid for visual interpretation of functional brain images. The Journal of Nuclear Medicine, 35(6), 949-54.

Morel, A. (2007). Stereotactic Atlas of the Human Thalamus and Basal Ganglia. Boca Raton: CRC Press.
Mori, S., Wakana, S., Nagae-Poetscher, L. M., \& van Zijl, P. C. (2005). MRI Atlas of Human White Matter. Amsterdam: Elsevier.

Mori, S., Oishi, K., Faria, A. V., \& Miller, M. I. (2013). Atlas-based neuroinformatics via MRI: harnessing information from past clinical cases and quantitative image analysis for patient care. Annual Review of Biomedical Engineering, 15, 71-92.

Mouches, P., \& Forkert, N. D. (2019). A statistical atlas of cerebral arteries generated using multi-center MRA datasets from healthy subjects. Scientific Data, 6, 29. https://doi.org/10.1038/s41597019-0034-5.

Naidich, ThP., Duvernoy, H. M., Delman, B. N., Sorensen, A. G., Kollias, S. S., \& Haacke, E. M. (2009). Duvernoy's Atlas of the Human Brain Stem and Cerebellum. Wien - New York: Springer.

Najdenovska, E., Alemán-Gómez, Y., Battistella, G., Descoteaux, M., Hagmann, P., Jacquemont, S., Maeder, P., Thiran, J. P., Fornari, E., \& Bach Cuadra, M. (2018). In-vivo probabilistic atlas of human thalamic nuclei based on diffusion- weighted magnetic resonance imaging. Scientific Data, 5, 180270. https://doi.org/10.1038/sdata. 2018.270.

Nowacki, A., Nguyen, T. A., Tinkhauser, G., Petermann, K., Debove, I., Wiest, R., \& Pollo, C. (2018). Accuracy of different threedimensional subcortical human brain atlases for DBS-lead localisation. NeuroImage: Clinical, 20, 868-874.

Nowinski, W. L., Fang, A., Nguyen, B. T., Raphel, J. K., Jagannathan, L., Raghavan, R., Bryan, R. N., \& Miller, G. (1997a). Multiple brain atlas database and atlas-based neuroimaging system. Computer Aided Surgery, 2(1), 42-66.

Nowinski, W. L., Bryan, R. N., \& Raghavan, R. (1997b). The Electronic Clinical Brain Atlas. Multiplanar Navigation of the Human Brain. New York: Thieme.

Nowinski, W. L. (1998). Anatomical targeting in functional neurosurgery by the simultaneous use of multiple Schaltenbrand-Wahren brain atlas microseries. Stereotactic and Functional Neurosurgery, 71(3), 103-116.

Nowinski, W. L., Yang, G. L., \& Yeo, T. T. (2000a). Computer-aided stereotactic functional neurosurgery enhanced by the use of the multiple brain atlas database. IEEE Transactions on Medical Imaging, 19(1), 62-69.

Nowinski, W. L., Thirunavuukarasuu, A., \& Kennedy, D. N. (2000b). Brain Atlas for Functional Imaging. Clinical and Research Applications. New York: Thieme.

Nowinski, W. L. (2001a). Computerized brain atlases for surgery of movement disorders. Seminars in Neurosurgery, 12(2), 183-194.

Nowinski, W. L. (2001b). Modified Talairach landmarks. Acta Neurochirurgica, 143(10), 1045-1057.

Nowinski, W. L., Belov, D., \& Benabid, A. L. (2002a). A communitycentric Internet portal for stereotactic and functional neurosurgery with a probabilistic functional atlas. Stereotactic and Functional Neurosurgery, 79, 1-12.

Nowinski, W. L., Thirunavuukarasuu, A., \& Bryan, R. N. (2002b). The Cerefy Atlas of Brain Anatomy. An Introduction to Reading Radiological Scans for Students, Teachers, and Researchers. New York: Thieme.

Nowinski, W. L., \& Belov, D. (2003). The Cerefy Neuroradiology Atlas: A Talairach-Tournoux atlas-based tool for analysis of neuroimages available over the Internet. NeuroImage, 20(1), 50-57.

Nowinski, W. L., \& Thirunavuukarasuu, A. (2003). A locus-driven mechanism for rapid and automated atlas-assisted analysis of functional images by using the Brain Atlas for Functional Imaging. Neurosurgical Focus, 15(1), Article 3.

Nowinski, W. L., Belov, D., \& Benabid, A. L. (2003). An algorithm for rapid calculation of a probabilistic functional atlas of subcortical structures from electrophysiological data collected during functional neurosurgery procedures. NeuroImage, 18(1), 143-155. 
Nowinski, W. L. (2004). Co-registration of the Schaltenbrand-Wahren microseries with the probabilistic functional atlas. Stereotactic and Functional Neurosurgery, 82, 142-146.

Nowinski, W. L., \& Thirunavuukarasuu, A. (2004). The Cerefy Clinical Brain Atlas on CD-ROM. New York: Thieme.

Nowinski, W. L., \& Belov, D. (2005). Towards atlas-assisted automatic interpretation of MRI morphological brain scans in the presence of tumor. Academic Radiology, 12, 1049-1057.

Nowinski, W. L., Thirunavuukarasuu, A., \& Benabid, A. L. (2005a). The Cerefy Clinical Brain Atlas. Extended Edition with Surgery Planning and Intraoperative Support. New York: Thieme.

Nowinski, W. L., Belov, D., Pollack, P., \& Benabid, A. L. (2005b). Statistical analysis of 168 bilateral subthalamic nucleus implantations by means of the probabilistic functional atlas. Neurosurgery, 57(4 Suppl), 319-330.

Nowinski, W. L., Qian, G., Bhanu Prakash, K. N., Thirunavuukarasuu, A., Hu, Q. M., Ivanov, N., Parimal, A. S., Runge, V. M., \& Beauchamp, N. J. (2006). Analysis of ischemic stroke MR images by means of brain atlases of anatomy and blood supply territories. Academic Radiology, 13(8), 1025-34.

Nowinski, W. L. (2009). Anatomical and probabilistic functional atlases in stereotactic and functional neurosurgery. In: Textbook of Stereotactic and Functional Neurosurgery (eds. Lozano A, Gildenberg P, Tasker R, pp. 395-441), 2ed edition. Springer, Berlin.

Nowinski, W. L., \& Thirunavuukarasuu, A. (2009). Quantification of spatial consistency in the Talairach and Tournoux stereotactic atlas. Acta Neurochirgica, 151(10), 1207-1213.

Nowinski, W. L., Thirunnavuukarasuu, A., Volkau, I., Marchenko, Y., Aminah, B., Puspitasaari, F., \& Runge, V. M. (2009a). A threedimensional interactive atlas of cerebral arterial variants. Neuroinformatics, 7(4), 255-264.

Nowinski, W. L., Thirunavuukarasuu, A., Volkau, I., Marchenko, Y., \& Runge, V. M. (2009b). The Cerefy Atlas of Cerebral Vasculature. New York: Thieme.

Nowinski, W. L., Thirunavuukarasuu, A., Ananthasubramaniam, A., Chua, A., Qian, B. C., Nowinska, G., Marchenko, N. G., Volkau, Y. I (2009c). Automatic testing and assessment of neuroanatomy using a digital brain atlas: method and development of computerand mobile-based applications. Anatomical Sciences Education, 2(5), 244-252.

Nowinski, W. L., Chua, B. C., Volkau, I., Puspitasari, F., Marchenko, Y., Runge, V. M., \& Knopp, M. V. (2010). Simulation and assessment of cerebrovascular damage in deep brain stimulation using a stereotactic atlas of vasculature and structure derived from multiple 3T and 7T scans. Journal of Neurosurgery, 113(6), 1234-1241.

Nowinski, W. L., Chua, B. C., Puspitasari, F., Volkau, I., Marchenko, Y., \& Knopp, M. V. (2011a). Three-dimensional reference and stereotactic atlas of human cerebrovasculature from 7 T. NeuroImage, 55(3), 986-998.

Nowinski, W. L., Chua, B. C., Qian, G. Y., Marchenko, Y., Puspitasari, F., Nowinska, N. G., \& Knopp, M. V. (2011b). The Human Brain in 1492 Pieces: Structure, Vasculature, and Tracts. New York: Thieme.

Nowinski, W. L., Chua, B. C., Qian, G. Y., \& Nowinska, N. G. (2012a). The human brain in 1700 pieces: design and development of a threedimensional, interactive and reference atlas. Journal of Neuroscience Methods, 204(1), 44-60.

Nowinski, W. L., Chua, B. C., Yang, G. L., \& Qian, G. Y. (2012b). Three-dimensional interactive human brain atlas of white matter tracts. Neuroinformatics, $10(1), 33-55$.

Nowinski, W. L., Johnson, A., Chua, B. C., \& Nowinska, N. G. (2012c). Three-dimensional interactive and stereotactic atlas of cranial nerves and nuclei correlated with surface neuroanatomy, vasculature and magnetic resonance imaging. Journal of Neuroscience Methods, 206(2), 205-216.
Nowinski, W. L., \& Chua, B. C. (2013a). Bridging neuroanatomy, neuroradiology and neurology: three-dimensional interactive atlas of neurological disorders. The Neuroradiology Journal, 26(3), 252262.

Nowinski, W. L., \& Chua, B. C. (2013b). The Complete Human Brain (version 1.0 for $\mathrm{iPad}$ ). New York: Thieme. 2013/AppStore.

Nowinski, W. L., Chua, B. C., Johnson, A., Qian, G., Poh, L. E., Wut Yi, S. H., Aminah, B., \& Nowinska, N. G. (2013c). Three-dimensional interactive and stereotactic atlas of head muscles and glands correlated with cranial nerves and surface and sectional neuroanatomy. Journal of Neuroscience Methods, 215(1), 12-18.

Nowinski, W. L., \& Chua, B. C. (2014). The Human Brain in 1969 Pieces: Structure, Vasculature, Tracts, Cranial Nerves, Systems, Head Muscles, and Glands (version 2.0). New York: Thieme.

Nowinski, W. L., Gupta, V., Qian, G. Y., et al. (2014a). Population-based stroke atlas for outcome prediction: method and preliminary results for ischemic stroke from CT. PLoS One, 9(8), e102048. https://doi. org/10.1371/journal.pone.0102048. eCollection 2014.

Nowinski, W. L., Chua, B. C., \& Wut Yi, S. H. (2014b). 3D Atlas of Neurologic Disorders. New York: Thieme.

Nowinski, W. L., Chua, B. C., \& Ngai, V. (2014c). The 3D Brain Atlas (version 1.0 for Android). New York: Thieme.

Nowinski, W. L., Chua, B. C., Thaung, T. S. L., \& Wut Yi, S. H. (2015a). The Human Brain, Head and Neck in 2953 Pieces. New York: Thieme. http://www.thieme.com/nowinski/.

Nowinski, W. L. Thaung TSL, Chua BC, Wut Yi SH, Yang Y, Urbanik A. (2015b). Three-dimensional stereotactic atlas of the extracranial vasculature correlated with the intracranial vasculature, cranial nerves, skull and muscles. The Neuroradiology Journal, 28(2), 190-197.

Nowinski, W. L. Thaung TSL, Chua, B. C. Wut Yi SH, Ngai, V. Yang Y, Chrzan, R. Urbanik A. (2015c). Three-dimensional stereotactic atlas of the adult human skull correlated with the brain, cranial nerves and intracranial vasculature. Journal of Neuroscience Methods, 246, 6574.

Nowinski, W. L. (2016). Usefulness of brain atlases in neuroradiology: current status and future potential. The Neuroradiology Journal, 29(4), 260-268.

Nowinski, W. L. (2017a). Human brain atlasing: past, present and future. The Neuroradiology Journal, 30(6), 504-519.

Nowinski, W. L. (2017b). 3D atlas of the brain, head and neck in 2953 pieces. Neuroinformatics, 15(4), 395-400.

Nowinski, W. L. (2020). Human brain atlases in stroke management. Neuroinformatics. https://doi.org/10.1007/s12021-020-09462-y.

Oishi, K., Linda Chang, L., \& Huang, H. (2019). Baby brain atlases. Neurolmage, 185, 865-880.

Ono, M., Kubik, S., \& Abernathey, C. D. (1990). Atlas of the Cerebral Sulci. Stuttgart - New York: Georg Thieme Verlag/Thieme Medical Publishers.

Orrison, W. W. Jr. (1995). Atlas of Brain Function. New York: Thieme.

Ou, Y., Akbari, H., Bilello, M., et al. (2014). Comparative evaluation of registration algorithms in different brain databases with varying difficulty: results and insights. IEEE Transactions on Medical Imaging, 33(10), 2039-2065.

Ou, Y., Zöllei, L., Retzepi, K., Castro, V., Bates, S. V., Pieper, S., Andriole, K. P., Murphy, S. N., Gollub, R. L., \& Grant, P. E. (2017). Using clinically acquired MRI to construct age-specific ADC atlases: Quantifying spatiotemporal ADC changes from birth to 6-year old. Human Brain Mapping, 38(6), 3052-3068.

Passat, N., Ronse, C., Baruthio, J., Armspach, J. P., Maillot, C. (2006). Magnetic resonance angiography: from anatomical knowledge modeling to vessel segmentation. Medical Image Analysis, 10(2): 259-274.

Pauli, W. M., Nili, A. N., \& Tyszka, J. M. (2018). A high-resolution probabilistic in vivo atlas of human subcortical brain nuclei. Scientific Data, 5, 180063. 
Petersen, M. V., Mlakar, J., Haber, S. N., Parent, M., Smith, Y., Strick, P. L., Griswold, M. A., \& McIntyre, C. C. (2019). Holographic reconstruction of axonal pathways in the human brain. Neuron, 104(6), 1056-1064.e3. https://doi.org/10.1016/j.neuron.2019.09.030.

Poletti, C. E. (1985). Stereo atlas of operative microneurosurgery. Mosby, St. Louis. .

Rohlfing, T., Zahr, N. M., Sullivan, E. V., \& Pfefferbaum, A. (2010). The SRI24 multichannel atlas of normal adult human brain structure. Human Brain Mapping, 31(5), 798-819.

Roland, P. E., \& Zilles, K. (1994). Brain atlases-a new research tool. Trends in Neurosciences, 17, 458-467.

Roniotis, A., Marias, K., Sakkalis, V., Manikis, G. C., \& Zervakis, M. (2012). Simulating radiotherapy effect in high-grade glioma by using diffusive modeling and brain atlases. Journal of Biomedicine and Biotechnology, 2012, Article ID 715812. https://doi.org/10. 1155/2012/715812.

Sadato, N., Morita, K., Kasai, K., Fukushi, T., Nakamura, K., Nakazawa, E., Okano, H., \& Okabe, S. (2019). Neuroethical issues of the Brain/ MINDS Project of Japan. Neuron, 101(3), 385-389. https://doi.org/ 10.1016/j.neuron.2019.01.006

Sadikot, A. F., Chakravarty, M. M., Bertrand, G., Rymar, V. V., AlSubaie, F., \& Collins, D. L. (2011). Creation of computerized 3D MRI-integrated atlases of the human basal ganglia and thalamus. Frontiers in Systems Neuroscience, 5, 71.

Saygin, Z. M., Kliemann, D., Iglesias, J. E., van der Kouwe, A. J. W., Boyd, E., Reuter, M., Stevens, A., Van Leemput, K., McKee, A., Frosch, M. P., Fischl, B., \& Augustinack, J. C., Alzheimer's Disease Neuroimaging Initiative (2017). High-resolution magnetic resonance imaging reveals nuclei of the human amygdala: manual segmentation to automatic atlas. Neuroimage, 155, 370-382.

Scarabino, T., Salvolini, U., DiSalle, F., Duvernoy, H., \& Rabischong, P. (Eds.). (2006). Atlas of Morphology and Functional Anatomy of the Brain. Berlin: Springer.

Schaltenbrand, G., \& Bailey, W. (1959). Atlas of Stereotaxy of the Human Brain. Stuttgart: Georg Thieme Verlag.

Schaltenbrand, G., \& Wahren, W. (1977). Atlas of Stereotaxy of the Human Brain. Stuttgart: Georg Thieme Verlag.

Serra, L., Nowinski, W. L., Poston, T., Ng, H., Lee, C. M., Chua, G. G., \& Pillay, P. K. (1997). The Brain Bench: virtual tools for stereotactic frame neurosurgery. Medical Image Analysis, 1(4), 317-329.

Shattuck, D. W., Mirza, M., Adisetiyo, V., Hojatkashani, C., Salamon, G., Narr, K. L., Poldrack, R. A., Bilder, R. M., \& Toga, A. W. (2008). Construction of a 3D probabilistic atlas of human cortical structures. NeuroImage, 39(3), 1064-80.

Sim, K., Yang, G. L., Loh, D., Poon, L. Y., Sitoh, Y. Y., Verma, S., Keefe, R., Collinson, S., Chong, S. A., Heckers, S., Nowinski, W. L., \& Pantelis, C. (2009). White matter abnormalities and neurocognitive deficits associated with the passivity phenomenon in schizophrenia: a diffusion tensor imaging study. Psychiatry Research, 172(2), 121-7.

Sivaswamy, J., Thottupattu, A. J., Mehta, R., Sheelakumari, R., \& Kesavadas, C. (2019). Construction of Indian human brain atlas. Neurology India, 67(1), 229-234.

Speigel, E. A., \& Wycis, H. T. (1952). Stereoencephalotomy: Part I. Methods and Stereotactic Atlas of the Human Brain. New York: Grune and Stratton.

Spitzer, V. M., Ackerman, M. J., Scherzinger, A. L., \& Whitlock, D. G. (1996). The visible human male: a technical report. Journal of the American Medical Informatics Association, 3, 118-130.

Sramka, M., Ruzicky, E., \& Novotny, M. (1997). Computerized brain atlas in functional neurosurgery. Stereotactic and Functional Neurosurgery, 69, 93-98.

St-Jean, P., Sadikot, A. F., Collins, L., Clonda, D., Kasrai, R., Evans, A. C., \& Peters, T. M. (1998). Automated atlas integration and interactive three-dimensional visualization tools for planning and guidance in functional neurosurgery. IEEE Transactions on Medical Imaging, $17(5), 672-680$.

Sudhyadhom, A., Okun, M. S., Foote, K. D., Rahman, M., \& Bova, F. J. (2012). A three-dimensional deformable brain atlas for DBS targeting. I. Methodology for atlas creation and artifact reduction. The Open Neuroimaging Journal, 6, 92-98.

Sundsten, J. W., Brinkley, J. F., Eno, K., \& Prothero, J. (1994). The Digital Anatomist. Interactive Brain Atlas. CD ROM for the Macintosh. Seattle: University of Washington.

Sunkin, S. M., Ng, L., Lau, C., Dolbeare, T., Gilbert, T. L., Thompson, C. L., Hawrylycz, M., \& Dang, C. (2013). Allen Brain Atlas: an integrated spatio-temporal portal for exploring the central nervous system. Nucleic Acids Research, 41(Database issue), D996-D1008.

Talairach, J., David, M., \& Tournoux, P. (1957). Atlas d'Anatomie Stereotaxique des Noyaux Gris Centraux. Paris: Masson.

Talairach, J., \& Tournoux, P. (1988). Co-Planar Stereotactic Atlas of the Human Brain. Stuttgart - New York: Thieme.

Talairach, J., \& Tournoux, P. (1993). Referentially Oriented Cerebral MRI Anatomy: Atlas of Stereotaxic Anatomical Correlations for Gray and White Matter. Stuttgart: Thieme.

Takayoshi, M., \& Hirano, A. (1978). Atlas of the Human Brain for Computerized Tomography. United States: Igaku Shoin Medical Publishers.

Tang, Y., Hojatkashani, C., Dinov, I. D., Sun, B., Fan, L., Lin, X., Qi, H., Hua, X., Liu, S., \& Toga, A. W. (2010). The construction of a Chinese MRI brain atlas: A morphometric comparison study between Chinese and Caucasian cohorts. Neuroimage, 51, 33-41.

Taso, M., Troter, A. L., Sdika, M., Ranjeva, J. P., Guye, M., Bernard, M., \& Callot, V. (2013). Construction of an in vivo human spinal cord atlas based on high-resolution MR images at cervical and thoracic levels: preliminary results. Magnetic Resonance Materials in Physics, Biology and Medicine, 27, 257-267.

Thiebaut de Schotten, M., Croxson, P. L., \& Mars, R. B. (2018).Largescale comparative neuroimaging: Where are we and what do we need?Cortex. https://doi.org/10.1016/j.cortex.2018.11.028.

Tiede, U., Bomans, M., Hoehne, K. H., Pommert, A., Riemer, M., Schiemann, Th, Schubert, R., \& Lierse, W. (1996). A computerized three-dimensional atlas of the human skull and brain. In E. D. Bigler (Ed.), Neuroimaging I. Human Brain Function (Assessment and Rehabilitation) (pp. 185-197). Boston: Springer.

Thompson, P. M., Woods, R. P., Mega, M. S., \& Toga, A. W. (2000). Mathematical/computational challenges in creating deformable and probabilistic atlases of the human brain. Human Brain Mapping, 9(2), 81-92.

Thompson, P. M., Mega, M. S., Woods, R. P., et al. (2001). Cortical change in Alzheimer's disease detected with a disease-specific population-based brain atlas. Cerebral Cortex, 11(1), 1-16.

Toga, A. W., \& Thompson, P. M. (2005). Brain atlases of normal and diseased populations. International Review of Neurobiology, 66, $1-$ 54.

Toga, A. W., Thompson, P. M., Mori, S., Amunts, K., \& Zilles, K. (2006). Towards multimodal atlases of the human brain. Nature Reviews Neuroscience, 7(12), 952-966.

Tzourio-Mazoyer, N., Landeau, B., Papathanassiou, D., Crivello, F., Etard, O., Delcroix, N., Mazoyer, B., Joliot, M. (2002). Automated anatomical labeling of activations in SPM using a macroscopic anatomical parcellation of the MNI MRI single-subject brain. Neuroimage, 15(1):273-289.

Van Buren, J. M., \& Borke, R. C. (1972). Variations and Connections of the Human Thalamus. Berlin: Springer.

Van Essen, D. C. (2013). Cartography and connectomes. Neuron, 80, $775-790$.

Van Essen, D. C., Smith, S. M., Barch, D. M., Behrens, T. E. J., Yacoub, E., \& Ugurbil, K. (2013). The WU-Minn Human Connectome Project: An overview. NeuroImage, 80, 62-79. 
Van Essen, D. C., Smith, J., Glasser, M. F., et al. (2017). The Brain Analysis Library of Spatial maps and Atlases (BALSA) database. NeuroImage, 144, 270-274.

Varoquaux, G., Schwartz, Y., Poldrack, R. A., Gauthier, B., Bzdok, D., Poline, J. B., \& Thirion, B. (2018). Atlases of cognition with largescale human brain mapping. PLOS Computational Biology, 14(11), e1006565. https://doi.org/10.1371/journal.pcbi.1006565 (eCollection 2018 Nov).

Visible Body. (n.d.). Human Anatomy Atlas. Available at: http://www. visiblebody.com.

Vogt, C., \& Vogt, O. (1919). Allgemeinere Ergebnisse unserer Hirnforschung (English Translation: Results of our brain research in a broader context). Journal of Neurology and Psychology, 25, 292-398.

Von Economo, C., \& Koskinas, G. N. (1925). Die Cytoarchitektonik der Hirnrinde des Erwachsenen Menschen. Berlin: Springer.

Wild, H. M., Heckemann, R. A., Studholme, C., \& Hammers, A. (2017). Gyri of the human parietal lobe: Volumes, spatial extents, automatic labelling, and probabilistic atlases. PLoS One, 12(8), e0180866. https://doi.org/10.1371/journal.pone.0180866. eCollection 2017.

Wolf, I., Vetter, M., Wegner, I., Böttger, T., Nolden, M., Schöbinger, M., Hastenteufel, M., Kunert, T., \& Meinzer, H. P. (2005). The medical imaging interaction toolkit. Medical Image Analysis, 9(6), 594-604.

Wu, D., Ma, T., Ceritoglu, C., Li, Y., Chotiyanonta, J., Hou, Z., Hsu, J., Xu, X., Brown, T., Miller, M. I., \& Mori, S. (2016). Resource atlases for multi-atlas brain segmentations with multiple ontology levels based on T1-weighted MRI. Neuroimage, 125, 120-130. https:// doi.org/10.1016/j.neuroimage.2015.10.042.

Yeh, F. C., Panesar, S., Fernandes, D., Meola, A., Yoshino, M., Fernandez-Miranda, J. C., Vettel, J. M., \& Verstynen, T. (2018). Population-averaged atlas of the macroscale human structural connectome and its network topology. Neuroimage, 178, 57-68.
Yelnik, J., Bardinet, E., Dormont, D., et al. (2007). A three-dimensional, histological and deformable atlas of human basal ganglia. I. Atlas construction based on immunohistochemical and MRI data. Neurolmage, 34(2), 618-38.

Yoshida, M. (1987). Creation of a three-dimensional atlas by interpolation from Schaltenbrand-Bailey's atlas. Applied Neurophysiology, 50(1-6), 45-48.

Yushkevich, P. A., Avants, B. B., Pluta, J., Das, S., Minkoff, D., et al. (2009). A high-resolution computational atlas of the human hippocampus from postmortem magnetic resonance imaging at $9.4 \mathrm{~T}$. NeuroImage; 44:385-98.

Zaffino, P., Ciardo, D., Raudaschl, P., Fritscher, K., Ricotti, R., Alterio, D., et al. (2018). Multi atlas based segmentation: should we prefer the best atlas group over the group of best atlases? Physics in Medicine and Biology, 63(12), 12NT01. https://doi.org/10.1088/ 1361-6560/aac712

Zhang, Y., Wei, H., Cronin, M. J., He, N., Yan, F., \& Liu, C. (2018). Longitudinal atlas for normative human brain development and aging over the lifespan using quantitative susceptibility mapping. Neuroimage, 171, 176-189.

Zhang, S. X., Heng, P. A., \& Liu, Z. J. (2003). Atlas of Chinese visible human (Male and Female). China: Science Press.

Zhao, Y., Dong, Q., Chen, H., Iraji, A., Li, Y., Makkie, M., Kou, Z., Liu, T. (2017). Constructing fine-granularity functional brain network atlases via deep convolutional autoencoder. Medical Image Analysis, 42(2), 200-211.

Zuo, X. N., He, Y., Betzel, R. F., et al. (2017). Human connectomics across the life span. Trends in Cognitive Sciences, 21(1), 32-45.

Publisher's Note Springer Nature remains neutral with regard to jurisdictional claims in published maps and institutional affiliations. 